\title{
Transcriptome Analysis and
} Characterization of Chemosensory Genes in the Forest Pest, Dioryctria abietella (Lepidoptera: Pyralidae)

\author{
Zheng-Quan Wang, Chun Wu, Gen-Ceng Li, Shu-Mei Nuo, Ning-Na Yin and \\ Nai-Yong Liu*
}

Key Laboratory of Forest Disaster Warning and Control of Yunnan Province, Southwest Forestry University, Kunming, China

OPEN ACCESS

Edited by:

Peng He,

Guizhou University, China

Reviewed by:

Yihan Xia,

Chalmers University of Technology,

Sweden

Wei Xu,

Murdoch University, Australia William Benjamin Walker III,

Agricultural Research Service,

United States Department

of Agriculture (USDA-ARS),

United States

*Correspondence:

Nai-Yong Liu

naiyong_2013@163.com

Specialty section:

This article was submitted to Evolutionary and Population Genetics,

a section of the journal

Frontiers in Ecology and Evolution

Received: 27 July 2021

Accepted: 20 September 2021

Published: 14 October 2021

Citation:

Wang Z-Q, Wu C, Li G-C

Nuo S-M, Yin N-N and Liu N-Y (2021)

Transcriptome Analysis

and Characterization

of Chemosensory Genes in the Forest

Pest, Dioryctria abietella (Lepidoptera:

Pyralidae).

Front. Ecol. Evol. 9:748199.

doi: 10.3389/fevo.2021.748199
In Lepidoptera, RNA sequencing has become a useful tool in identifying chemosensory genes from antennal transcriptomes, but little attention is paid to non-antennal tissues. Though the antennae are primarily responsible for olfaction, studies have found that a certain number of chemosensory genes are exclusively or highly expressed in the nonantennal tissues, such as proboscises, legs and abdomens. In this study, we report a global transcriptome of 16 tissues from Dioryctria abietella, including chemosensory and non-chemosensory tissues. Through Illumina sequencing, totally 952,658,466 clean reads were generated, summing to 142.90 gigabases of data. Based on the transcriptome, 235 chemosensory-related genes were identified, comprising 42 odorant binding proteins (OBPs), 23 chemosensory proteins (CSPs), 75 odorant receptors (ORs), 62 gustatory receptors (GRs), 30 ionotropic receptors (IRs), and 3 sensory neuron membrane proteins (SNMPs). Compared to a previous study in this species, 140 novel genes were found. A transcriptome-wide analysis combined with PCR results revealed that except for GRs, the majority of other five chemosensory gene families in Lepidoptera were expressed in the antennae, including 160 chemosensory genes in $D$. abietella. Using phylogenetic and expression profiling analyses, members of the six chemosensory gene repertoires were characterized, in which 11 DabiORs were candidates for detecting female sex pheromones in D. abietella, and DabiOR23 may be involved in the sensing of plant-derived phenylacetaldehyde. Intriguingly, more than half of the genes were detected in the proboscises, and one fourth of the genes were found to have the expression in the legs. Our study not only greatly extends and improves the description of chemosensory genes in $D$. abietella, but also identifies potential molecular targets involved in olfaction, gustation and non-chemosensory functions for control of this pest.

Keywords: Dioryctria abietella, transcriptome, chemosensory gene, phylogenetic analysis, expression profile

\section{INTRODUCTION}

Over the last decade, Illumina sequencing has been applied to a diverse range of insects regarding tissue transcriptomes (Kawahara et al., 2019; McKenna et al., 2019). Taking the Lepidoptera as an example, we refer to the studies on the identification of chemosensory-related genes derived from antennal transcriptomes, and find that at least 55 moth species, including Dioryctria abietella in this 
study, have described chemosensory gene families involved in olfaction, gustation, development, insecticide resistance and even the sensation of humidity and temperature, i.e., odorant binding proteins (OBPs), chemosensory proteins (CSPs), odorant receptors (ORs), gustatory receptors (GRs), ionotropic receptors (IRs) and sensory neuron membrane proteins (SNMPs) (Agnihotri et al., 2016; Pelosi et al., 2018; Robertson, 2019; $\mathrm{Xu}, 2020$; Montagné et al., 2021). Such great attention to chemosensory genes in moth antennae is attributable to their importance during the processes of smell and taste reception, as they mediate chemosensory-related behaviors of moths, such as the seeking of feeding or ovipositing host plants, the escape of dangerous signals and the recognition of conspecific partners (Cury et al., 2019; Zhang et al., 2019; Liu X. L. et al., 2020; Fleischer and Krieger, 2021). Through transcriptomic sequencing and analyses, we are able to explore the adaptation and specialization of moths to host, non-host plants or the constantly changing habitats, and identify candidate molecular targets associated with chemosensation, such as OBPs, CSPs, ORs, GRs, IRs, and SNMPs facilitating the screening of behaviorally active compounds by a reverse chemical ecology strategy.

During the process of olfactory reception in insects, two classes of binding proteins of OBPs and CSPs are responsible for filtering a variety of odorant molecules in the surrounding environment, as the first barriers for receiving and sensing chemical signals (Leal, 2013; Pelosi et al., 2018). Outside the olfactory roles, some members of OBPs or CSPs that are exclusively or highly expressed in gustatory or non-sensory organs have been found to be involved in additional physiological roles, such as taste, development, flight and insecticide resistance (Pelosi et al., 2018; Wang et al., 2020).

With the discovery of three chemosensory receptor gene families in D. melanogaster (Clyne et al., 1999, 2000; Benton et al., 2009), to date a large number of ORs, GRs and IRs have been identified and characterized in Diptera (Nozawa and Nei, 2007; Croset et al., 2010), Lepidoptera (Engsontia et al., 2014; Xu, 2020; Yin et al., 2021), Coleoptera (Andersson et al., 2019; Mitchell et al., 2020; Mitchell and Andersson, 2021), Hemiptera (Smadja et al., 2009; Liu Y. et al., 2021), and Hymenoptera (Ferguson et al., 2021; Obiero et al., 2021). In insects, ORs are expressed in sensilla basiconica and sensilla trichoidea separately responsible for general odorants (i.e., general ORs) and sex pheromones (i.e., pheromone receptors, PRs) (Krieger et al., 2009; de Fouchier et al., 2017; Guo et al., 2020), while olfactory sensory neurons expressing IRs are distributed in sensilla coeloconica sensitive to amines, acids, alcohols and aldehydes (Yao et al., 2005; Silbering et al., 2011; Rytz et al., 2013). Beyond olfaction, IRs are dedicated to the detection of humidity, temperature or tastants (Stewart et al., 2015; Enjin et al., 2016; Knecht et al., 2016; Hou et al., 2021). Compared with ORs and IRs, this GR gene repertoire possesses more variable gene numbers, ranging from 45 in Manduca sexta to 237 in Spodoptera litura (Koenig et al., 2015; Cheng T. et al., 2017). This variation is possibly correlated with host diversity, as members of an expanded bitter GRs clade primarily respond to plant secondary metabolites (Xu et al., 2016; Kasubuchi et al., 2018; Zhang et al., 2019). Besides the bitter receptors, other GR members in moths could detect sugars, fructose and carbon dioxide $\left(\mathrm{CO}_{2}\right)$, and share relatively high conservation in sequences and numbers (Zhang et al., 2011; Xu et al., 2012; Xu and Anderson, 2015; Ning et al., 2016; $\mathrm{Xu}, 2020)$.

Aside from the ORs, GRs, and IRs described above, a relatively small number of transmembrane proteins, SNMPs, are described in insects. In most species, two SNMPs are ubiquitous, representing SNMP1 and SNMP2 (Vogt et al., 2009). In Lepidoptera, the third SNMP gene subfamily was identified, bringing the numbers of SNMPs to three in some species (Liu et al., 2015; Zhang et al., 2020). More recently, a study reported 4 SNMP-encoding genes in a zygaenid species, Achelura yunnanensis, with two gene variants in the SNMP2 subfamily (Li G. C. et al., 2021). Although SNMP genes have been reported for over two decades, their functional studies are limited to members of the SNMP1 group which are involved in the sensing of sex pheromones (Pregitzer et al., 2014; Xu et al., 2021).

The coneworm, D. abietella (Lepidoptera: Pyralidae), is an oligophagous pest where its larvae feed on cones of the Pinaceae family, including the genus Pinus, Abies fabri (Mast.) Craib., Picea abies (L.) Karst., and P. likiangensis var. linzhiensis (Rosenberg and Weslien, 2005; Song et al., 2020; Tang et al., 2020). Early studies have reported sex pheromone components $\quad[(3 Z, 6 Z, 9 Z, 12 Z, 15 Z)$-pentacosapentaene and $(9 Z, 11 E)$-tetradecadienyl acetate] of this species and their application in fields (Löfstedt et al., 1983, 2012). Apart from that, terpene compounds produced by host plants have been implicated to be attractive to this pest (Tang et al., 2020). However, little is known about molecular mechanisms underlying intraspecific communication between female and male moths, as well as interspecific interaction between this pest and host plants. More recently, Xing et al. (2021) described six chemosensory gene repertoires from $D$. abietella by antennal transcriptome analysis (15 OBPs, 18 CSPs, 65 ORs, 5 GRs, 24 IRs and 5 SNMPs), but the majority of which were partial sequences. Moreover, after our transcriptome-wide sequencing and comparative analyses of 16 tissues including the antennae in this species, the numbers of ORs, GRs, IRs, and SNMPs reported in the previous study were summed down to $42,4,14$, and 3 , respectively. Thus, our study has expanded upon those results here with the identification of 42 OBPs, 23 CSPs, 75 ORs, 62 GRs, $30 \mathrm{IRs}$ and 3 SNMPs in D. abietella, and provides an extensive resource for studying putative functional roles of chemosensory genes in this pest, coupled with expression profiling analyses.

\section{MATERIALS AND METHODS}

\section{Insects and Tissue Collection}

The last instar larvae and pupae of D. abietella were collected from pine cones of Pinus armandii in Zixi Mountain, Chuxiong city, Yunnan Province, China. Next, the larvae were reared in the laboratory until pupae emergence, and pupae were sexed and individually kept in cages. Emerged adults were supplied with $10 \%$ honey solution. Rearing conditions were as follows: $25 \pm 1{ }^{\circ} \mathrm{C}, 60 \pm 5 \%$ relative humidity and a 12-h light/dark cycle. 
For RNA sequencing (RNA-Seq) and expression profiling analyses, 16 tissues including 50 antennae, 100 proboscises, 20 heads without antennae and proboscises, 5 thoraxes, 3 abdomens, 30 legs, 50 wings of female or male moths, as well as 30 female pheromone glands with ovipositors and 30 male hairpencils were collected from 3-day-old moths. These collected tissues were immediately frozen in liquid nitrogen and ground by glass homogenizers. After completely homogenized, $1 \mathrm{~mL}$ of TRIzol reagent (TaKaRa, Dalian, Liaoning, China) was added to each tissue. The prepared samples were stored at $-70^{\circ} \mathrm{C}$ until RNA extraction.

\section{RNA Extraction and cDNA Preparation}

Total RNAs of various tissues were extracted by using TRIzol reagent (TaKaRa, Dalian, Liaoning, China), according to the manufacturer's protocols. Next, genomic DNA was digested with gDNA Eraser at $42^{\circ} \mathrm{C}$ for $2 \mathrm{~min}$. The purified RNA samples were used for construction of cDNA libraries and expression profiling analyses. In brief, cDNA templates of different tissues were synthesized with the PrimeScript ${ }^{\mathrm{TM}}$ RT reagent Kit (TaKaRa, Dalian, Liaoning, China).

\section{Library Construction and Sequencing}

First, we assessed the quality and quantity of RNA samples by using agarose gels, the NanoPhotometer ${ }^{\circledR}$ Spectrophotometer (IMPLEN, CA, United States), the Qubit ${ }^{\circledR} 2.0$ Fluorometer (Life Technologies, CA, United States), and the Bioanalyzer 2100 System (Agilent Technologies, CA, United States), respectively. Next, $1 \mu \mathrm{g}$ of total RNA for each tissue evenly mixed by three biological pools was used to constructed a cDNA library using the NEBNext ${ }^{\circledR}$ Ultra $^{\text {TM }}$ RNA Library Prep Kit for Illumina ${ }^{\circledR}$ (NEB Inc., United States). Lastly, the prepared libraries were sequenced with 150-bp paired-end reads on an Illumina $\mathrm{HiSeq}^{\mathrm{TM}}$ 2000 instrument.

After cDNA libraries were sequenced, redundant sequences were discarded from the resulting raw reads, including adapter, low quality and containing poly- $\mathrm{N}$ sequences. The qualityfiltered reads (clean reads) were assembled into transcripts by Trinity v2.5.1 (Grabherr et al., 2011) as the transcript transcriptome. Further, the assembled transcripts were clustered by Corset v1.05 (Davidson and Oshlack, 2014), and the longest transcript for each cluster was selected as one unigene. All the unigenes were pooled into the unigene transcriptome.

\section{Functional Annotation and Gene Expression Estimation}

To predict putative functional roles of unigenes, we annotated the unigenes into different databases, including NR [National Center for Biotechnology Information (NCBI) non-redundant protein sequences], NT (NCBI non-redundant nucleotide sequences), PFAM (Protein family), KOG/COG (EuKaryotic Orthologous Groups/Clusters of Orthologous Groups), SwissProt, KO (KEGG Ortholog) and GO (Gene Ontology).

Expression levels of unigenes in different tissues were calculated by mapping clean reads to the reference transcriptome of unigenes using RSEM v1.2.15 with default parameters
(Li and Dewey, 2011). The numbers of read counts for each gene were used to determine the expression levels by FPKM (fragments per kilobase of transcript sequence per millions base pairs sequenced) method (Trapnell et al., 2010). If one gene was identified only from the transcript transcriptome, its expression values in tissues were unavailable because the FPKM values were computed based on the reads mapped to the unigene transcriptome.

\section{Gene Identification and Comparison}

For the identification of chemosensory genes in D. abietella, two de novo transcriptomes were used, i.e., the transcript transcriptome and the unigene transcriptome. First, a homologybased search with TBLASTN, implemented in Geneious v10.1.3 ${ }^{1}$, was employed to identify genes from the transcriptomes, with queries of chemosensory genes from D. abietella, Galleria mellonella, Ostrinia furnacalis, and Bombyx mori (Zhang T. et al., 2015; Guo et al., 2017; Liu et al., 2018; Zhao et al., 2019; Jiang et al., 2021; Xing et al., 2021; Yin et al., 2021). In search of each query, we set $e$-value and maximum blast hits as $1 \mathrm{e}^{-5}$ and 20 , respectively. In addition, the identified genes were iteratively blasted against the two stand-alone transcriptomes of D. abietella until no new genes were found.

To compare the numbers of chemosensory genes expressed in antennae of adult Lepidoptera, we summarized the studies on chemosensory genes identified from antennal transcriptomes. Specially, if one gene was identified only from antennal transcriptomes, it was thought to have the expression in the antennae. Alternatively, when one gene was found from the non-antennal tissues, but its transcription in the antennae was evidenced by reverse transcription (RT)-PCR or quantitative real-time PCR (qPCR), this gene was also counted as antennae-expressed genes. Detailed information on sequencing tissues, gene numbers and references were seen in Supplementary Table 1.

\section{Phylogenetic Analysis}

In the trees of OBPs and CSPs, the proteins from B. mori, D. abietella and S. litura were selected (Gong et al., 2009; Xiao et al., 2021). The OR tree was inferred with the ORs from D. abietella, Helicoverpa armigera, and O. furnacalis (Zhang T. et al., 2015; Guo et al., 2020). Of these, 35 HarmORs previously characterized were included (Liu et al., 2013; Jiang et al., 2014; Guo et al., 2020; Yang and Wang, 2021). The IRs from B. mori, $D$. abietella, $H$. armigera and $O$. furnacalis were used to infer the tree (Zhang T. et al., 2015; Liu et al., 2018; Xing et al., 2021). In the GR tree, we selected the GRs from B. mori, $D$. abietella and $H$. armigera, in which 15 representatives in $H$. armigera $\left(\mathrm{CO}_{2}\right.$, sugar, GR43a-like and some bitter GRs known ligands) were included (Xu et al., 2016; Guo et al., 2017). In the SNMP tree, considering a relatively small gene repertoire in each species, we used the SNMPs from 14 lepidopteran species and D. melanogaster (Zhang et al., 2020). For the selection of SNMPs used in Lepidoptera, if possible, all SNMPs from the pyralid and crambid species were included. Multiple

${ }^{1}$ https://www.geneious.com/ 
alignments of the protein sequences were conducted under the L-INS-i algorithm using MAFFT v7.450 with default parameters (Katoh and Standley, 2013). The aligned sequences were used to construct the maximum-likelihood trees under the Whelan and Goldman (WAG) model, implemented in FastTree v2.1.11 (Price et al., 2010). In the phylogenetic analysis, chemosensory receptors and SNMPs with less than 200 amino acids were discarded, and OBPs and CSPs showing below 100 amino acids were removed. Tree edition and visualization were conducted using FigTree v1.4.4 $4^{2}$.

\section{Expression Profiling Analysis With PCR Approaches}

In the expression profiles of genes, full-length transcripts encoding DabiORs and GRs were selected, including DabiOR1OR54, Orco, and GR1-GR16. In the CSP, IR, and SNMP gene families, except for a pseudogenized DabiIR2, all the genes were selected. In the OBP gene family, we selected 32 DabiOBPs with specific or high expression in antennae. RT-PCR was employed to determine tissue- and sex-specific expression of genes in sequenced tissues. The reactions were performed on a TAdanced $96 \mathrm{G}$ instrument (Analytik Jena AG, Jena, Germany) with an annealing temperature of $58^{\circ} \mathrm{C}$ and 35 cycles. For quality control of cDNA templates, a reference gene, ribosomal protein L10 (DabiRPL10), was used. In the RT-PCR analyses, one of three biological templates used for transcriptome sequencing was first used. If the expression of one gene in tissues was inconsistent with its corresponding FPKM results, at least two biological replicates were conducted. Gene-specific primers were designed using Primer Premier 5 (Supplementary Table 2). RT-PCR raw data of genes including uncropped gel pictures were seen in Supplementary Figure 1.

Based on the phylogeny of ORs, we selected 11 candidate DabiPRs in D. abietella, and further detected their relative expression levels in antennae and other tissues using qPCR. Each reaction contained a total volume of $20 \mu \mathrm{L}$ mixture, consisting of $2 \mu \mathrm{L}$ of $\mathrm{cDNA}$, each $0.5 \mu \mathrm{L}$ of forward and reverse primers $(10 \mu \mathrm{M})$, and $10 \mu \mathrm{L}$ of Bestar ${ }^{\circledR}$ SybrGreen qPCR mastermix (DBI ${ }^{\circledR}$ Bioscience, Germany). The reactions were run with an annealing temperature of $58^{\circ} \mathrm{C}$ and 40 cycles on a LightCycler $^{\circledR} 96$ System (Roche Diagnostics). For each gene, three biological pools were conducted with three technical replicates for each pool. Two reference genes, ribosomal protein S4 and L8 (DabiRPS4 and RPL8), were used to compute the relative expression of target genes using the Q-GENE method (Muller et al., 2002; Simon, 2003). The amplification efficiencies of primers for target and reference genes were determined using fivefold dilutions of antennal cDNA. The specificity of the products was evaluated by a melting curve analysis. The primers were designed using Beacon Designer 8.14 (Supplementary Table 2). qPCR raw data of target and reference genes were seen in Supplementary Figure 2 and Supplementary Table 3, including cycle threshold (CT) values, melting curves and primer amplification efficiencies. Data represented mean \pm SEM. Statistical significance of gene

${ }^{2}$ http://tree.bio.ed.ac.uk/software/figtree/ expression levels among tissues was compared using a oneway analysis of variance (ANOVA), followed by the Fisher's least significant difference (LSD) test, implemented in IBM SPSS Statistics 21.0 (SPSS Inc., Chicago, IL, United States). $P<0.05$ was considered as significant difference.

\section{RESULTS AND DISCUSSION}

\section{The Transcriptome of Various Tissues in Dioryctria abietella}

Through the Illumina HiSeq ${ }^{\circledR} 2000$ sequencing technique, we constructed and sequenced 16 RNA-Seq libraries of female and male moths. This sequencing resulted in the generation of variable raw data, ranging from 52,058,094 reads in male heads to $75,443,066$ reads in male proboscises. After cleaning, approximately $99.85 \%$ of raw reads $(952,658,466)$ were obtained and set as clean reads, representing 463,121,204 in female tissues and 489,537,262 in males. The size of all the clean reads was summed to 142.90 gigabases (G). Such sequencing and analysis yielded a low error rate $(0.03 \%)$, high Phred values $(\mathrm{Q} 20=98.26 \%$ and Q30 = 94.69\%) and a moderate GC content (45.24\%) (Table 1). With an emphasis on the antennae responsible for olfaction, here our transcriptome sequencing obtained more raw data from $D$. abietella antennae (females: 58,464,276 sequences and males: 71,979,886 sequences) compared to previous studies in D. abietella $(47,005,976$ and $50,818,590$ reads for females and males, respectively) (Xing et al., 2021), and other two pyralid moths, G. mellonella $(41,665,706$ and 37,238,352 reads for females and males, respectively) (Zhao et al., 2019) and Plodia interpunctella (21,937,207 and 22,682,896 reads for females and males, respectively) (Jia et al., 2018). This may explain, to some extent, why $D$. abietella here possessed a larger number of ORs as members of this gene family were primarily enriched in the antennae (70 ORs in this study, 42 ORs in a previous study from D. abietella, 46 ORs in G. mellonella and 47 ORs in P. interpunctella) (Jia et al., 2018; Zhao et al., 2019; Xing et al., 2021).

All clean reads were subject to sequence assembly using Trinity v2.1.5. As a result, 435,990 transcripts were generated with the majority of below $301 \mathrm{bp}$. This Corset clustering further led to the yields of 172,189 unigenes, $57.71 \%$ of which were categorized into the sizes of 301-1000 bp (Supplementary Figure 3A). Functional annotation of all the unigenes showed that the NCBI NR database had the largest number of genes $(41,456)$ among seven databases, followed by GO $(33,051)$ and PFAM $(31,976)$. As many as 60,504 unigenes were presented in at least one database, whereas a relatively small number of genes (4546) were common to all seven databases (Supplementary Figure 3B). In the analyses of GO functions, 33,501 unigenes were annotated into different categories, representing 25, 20, and 10 functional terms in biological process, cell component and molecular function, respectively. In biological process, cellular process and metabolic process were the most abundant terms. Both cell and cell part accounted for the largest proportion in cell component. GO categories of molecular function were mainly composed of binding and 
TABLE 1 | Statistics of the transcriptome of various tissues in D. abietella.

\begin{tabular}{|c|c|c|c|c|c|c|c|}
\hline Tissue & Raw read & Clean read & Size (G) & Error(\%) & Q20(\%) & Q30(\%) & GC content( $\%)$ \\
\hline FA & $58,464,276$ & $58,395,372$ & 8.76 & 0.02 & 98.60 & 95.31 & 44.84 \\
\hline FPro & $54,190,778$ & $54,111,656$ & 8.12 & 0.03 & 97.97 & 94.11 & 45.04 \\
\hline $\mathrm{FH}$ & $52,180,720$ & $52,056,692$ & 7.80 & 0.03 & 97.91 & 94.10 & 42.89 \\
\hline $\mathrm{FT}$ & $72,497,030$ & $72,382,434$ & 10.86 & 0.03 & 97.94 & 94.06 & 45.08 \\
\hline $\mathrm{FAb}$ & $57,724,882$ & $57,653,700$ & 8.64 & 0.02 & 98.65 & 95.51 & 46.54 \\
\hline $\mathrm{FL}$ & $59,214,614$ & $59,126,418$ & 8.86 & 0.03 & 97.92 & 93.85 & 45.86 \\
\hline FW & $54,597,756$ & $54,509,940$ & 8.18 & 0.02 & 98.53 & 95.21 & 45.36 \\
\hline FPG & $54,964,100$ & $54,884,992$ & 8.24 & 0.02 & 98.64 & 95.49 & 46.21 \\
\hline MA & $71,979,886$ & $71,892,116$ & 10.78 & 0.03 & 97.94 & 94.03 & 44.49 \\
\hline MPro & $75,443,066$ & $75,325,052$ & 11.30 & 0.03 & 97.86 & 93.92 & 44.42 \\
\hline $\mathrm{MH}$ & $52,058,094$ & $51,949,624$ & 7.80 & 0.03 & 97.91 & 94.09 & 43.73 \\
\hline MT & $63,764,016$ & $63,682,986$ & 9.56 & 0.02 & 98.18 & 94.54 & 43.76 \\
\hline MAb & $58,079,532$ & $57,989,368$ & 8.70 & 0.02 & 98.47 & 95.04 & 46.56 \\
\hline$M L$ & $55,969,010$ & $55,875,530$ & 8.38 & 0.02 & 98.64 & 95.53 & 45.74 \\
\hline MW & $56,054,934$ & $55,973,766$ & 8.40 & 0.03 & 98.45 & 94.94 & 46.10 \\
\hline $\mathrm{MHp}$ & $56,913,050$ & $56,848,820$ & 8.52 & 0.02 & 98.56 & 95.28 & 47.19 \\
\hline Total/Mean & $954,095,744$ & $952,658,466$ & 142.90 & 0.03 & 98.26 & 94.69 & 45.24 \\
\hline
\end{tabular}

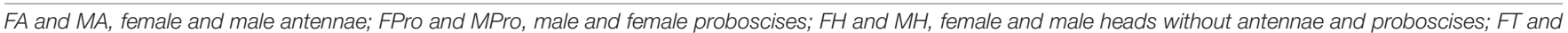

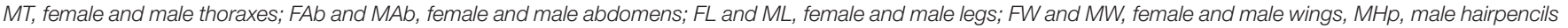
and FPG, female pheromone glands.

catalytic activities (Supplementary Figure 3C). In search of unigenes against the NCBI NR protein sequence database, D. abietella genes shared the highest homology to those from Amyelois transitella (52.65\%) (Supplementary Figure 3D).

\section{Identification of Chemosensory Genes in Dioryctria abietella}

We identified 235 chemosensory-related transcripts from the de novo assembled transcriptomes, comprising 42 OBPs, 23 CSPs, 75 ORs, 62 GRs, 30 IRs, and 3 SNMPs. Notably, DabiOR70 and 10 DabiGRs were found exclusively in the transcript transcriptome, but were partial sequences. Of the identified genes, 148 were predicted to have complete open reading frames (ORFs), with variable sizes of 139-340 amino acids for DabiOBPs, 102-290 for DabiCSPs, 357-476 for DabiORs, 372-482 for DabiGRs, 494844 for DabiIRs, and 523-526 for DabiSNMPs. The remaining 87 genes were fragments, more than half of which (46/87) belonged to members of the GR gene family, including a conserved $\mathrm{CO}_{2}$ receptor (DabiGR34) (Supplementary Table 4).

In comparison with a previous study on chemosensory genes in this species identified from the antennal transcriptome (15 OBPs, 18 CSPs, 42 ORs, 4 GRs, and 14 IRs) (Xing et al., 2021), our current transcriptome did not retrieve one CSP gene, namely DabiCSP2, but newly identified 140 genes encoding 27 OBPs, 6 CSPs, 33 ORs, 58 GRs, and 16 IRs. Of the identified $O B P s$ and CSPs, we followed the previous nomenclature systems, except for DabiPBP3, GOBP1, and GOBP2 that were designated according to their orthology to OBPs in other lepidopterans. For the chemosensory membrane protein gene families, due to their fragmented sequences and some incorrect genes in the previous study, we merged a number of gene fragments, corrected some genes and re-named them. This re-annotation led to the yields of $42 \mathrm{ORs}, 4 \mathrm{GRs}, 14 \mathrm{IRs}$, and 3 SNMPs in the previous study (Xing et al., 2021).
Among these, DabiOR5 and OR25 did not belong to the OR gene family and were identified as two parts of the ortholog of GR1 in the $\mathrm{CO}_{2}$ subclade, DabiIR19 was a member (DabiiGluR10) of ionotropic glutamate receptors, and DabiSNMP5 was discarded because it did not belong to SNMPs (Supplementary Table 4). Together, except for DabiSNMPs, our current study identified more chemosensory genes in other five gene families, largely attributed to transcriptomewide sequencing of multi-tissues. Meanwhile, this possibly reflected that some genes were expressed in non-antennal tissues, especially the GR gene repertoire.

\section{Antennae-Expressed Chemosensory Genes in Adult Moths}

With the emergence of RNA-Seq techniques, a large number of tissues in moths have been sequenced. Currently, we focused on a principle olfactory organ of adults, antenna, and compared the numbers of chemosensory genes expressed in the antennae. By using "antennae" and/or "transcriptome" and/or "chemosensory genes" as keywords to search web of science, we found that antennal tissues of 55 moth species including D. abietella have been sequenced, emphasizing the identification and characterization of chemosensory gene families. Subsequently, we combined antennal transcriptome, RT-PCR and qPCR data to determine the numbers of chemosensory genes in the antennae (Figure 1 and Supplementary Table 1).

This comprehensive and comparative analysis led to the identification of 1212 OBPs, 728 CSPs, 2698 ORs, 317 GRs, 844 $I R s$, and 80 SNMPs in adult antennae from 55 moths belonging to 17 families, including 37 DabiOBPs, 20 DabiCSPs, 70 DabiORs, 6 DabiGRs, 24 DabiIRs, and 3 DabiSNMPs. Expectedly, numerous OR members were detected in the antennae. However, the numbers of OR genes were variable among different species. For example, the OR numbers in 14 noctuid moths varied from 13 


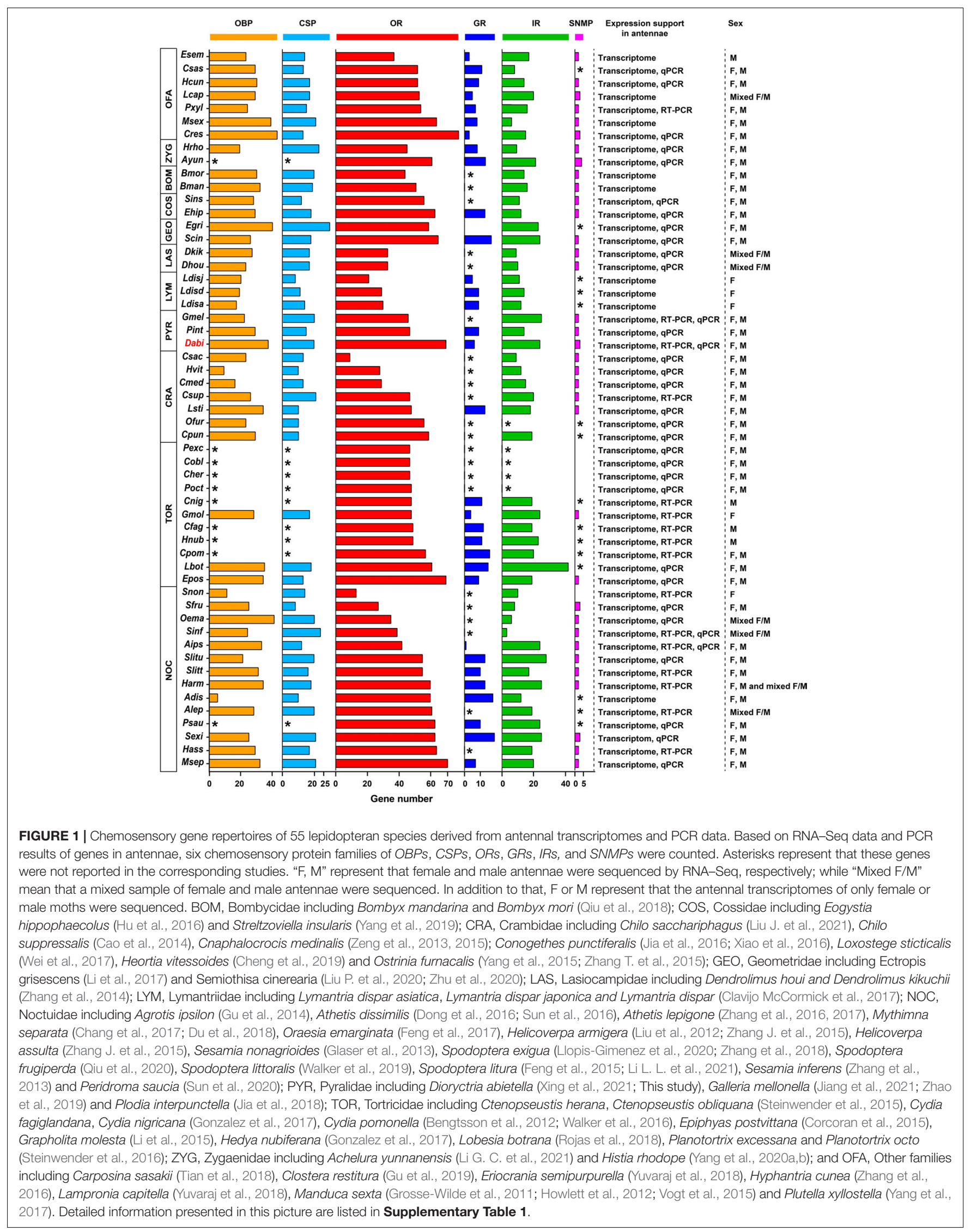


in Sesamia nonagrioides to 71 in Mythimna separate, while 9 in Chilo sacchariphagus and 78 in Clostera restitura were observed among species of the different families. Similarly, the numbers of the OBP and IR gene repertoires in the antennae were different across moths, with the range of 5 OBPs in Athetis dissimilis to 43 OBPs in C. restitura, and 3 IRs in Sesamia inferens to 42 IRs in Lobesia botrana. In contrast to the families of OBPs, ORs and IRs, the CSP, GR, and SNMP gene families harbored smaller members in the antennae. In particular, GR genes in 23 species were not identified or missed in the antennae, suggesting extremely low or no expression of the genes (Figure 1 and Supplementary Table 1).

Further, we concentrated on gene numbers of three gene families primarily involved in olfaction, i.e., OBPs, ORs, and IRs. Difference in the repertoire sizes of antennae-expressed OBPs, ORs, or IRs were possibly attributed to the following reasons: (1) sequencing depth as discussed above; (2) sequencing sexes such as $S$. nonagrioides, and (3) sequencing platforms or techniques (Figure $\mathbf{1}$ and Supplementary Table 1). In addition, it was also possible that a wide diversity of host plants drove the evolution of olfactory genes (Pelosi et al., 2018; Robertson, 2019; Auer et al., 2020; Yin et al., 2021). Although lepidopteran GRs, except for $\mathrm{CO}_{2}$-sensing receptors, were mainly expressed in gustatory-related tissues like proboscises and legs, they were indeed present in the antennae from D. abietella and other lepidopterans, including sugar, GR43a-like and some bitter receptors (Xu et al., 2016; Guo et al., 2017; Li G. C. et al., 2021). This may be correlated with contact chemosensation of antennae, as lepidopteran insects were able to touch or tap host plants using their antennae before feeding nectar or laying eggs (Ozaki et al., 2011; Briscoe et al., 2013; Agnihotri et al., 2016; Xu et al., 2016; Guo et al., 2017).

\section{Phylogenetic and Expression Profiling Analysis of Dioryctria abietella Odorant Binding Proteins}

Previously, lepidopteran OBPs were classified into six subfamilies based on sequence homology and conserved cysteines, i.e., pheromone binding proteins/general odorant binding proteins (PBP/GOBPs), antennal binding protein I (ABP I), ABP II, chemical sense-related lipophilic ligand binding proteins (CRLBPs), Minus-C OBPs and Plus-C OBPs (Gong et al., 2009). In the present study, 42 DabiOBPs were distributed in each subfamily, representing each five in $\mathrm{PBP} / \mathrm{GOBPs}$ and Minus$\mathrm{C}$ OBPs, each seven in ABP IIs and Plus-C OBPs, and each nine in ABP Is and CRLBPs. In most orthologous clades, there were 1:1:1 orthologs among three species. However, two subfamily expansions were observed in some species, including 9 BmorOBPs in Minus-C OBPs (each five in D. abietella and S. litura) and 17 SlitOBPs in ABP Is (8 in B. mori and 9 in D. abietella). In addition, the ortholog of PBP4, which was previously defined as a novel subclass of the Lepidopteraspecific PBP/GOBPs (Xiao et al., 2021), was not found in D. abietella (Figure 2A).

Expression profiles with RNA-Seq data revealed that the majority of DabiOBPs exhibited tissue-specific expression. Nearly

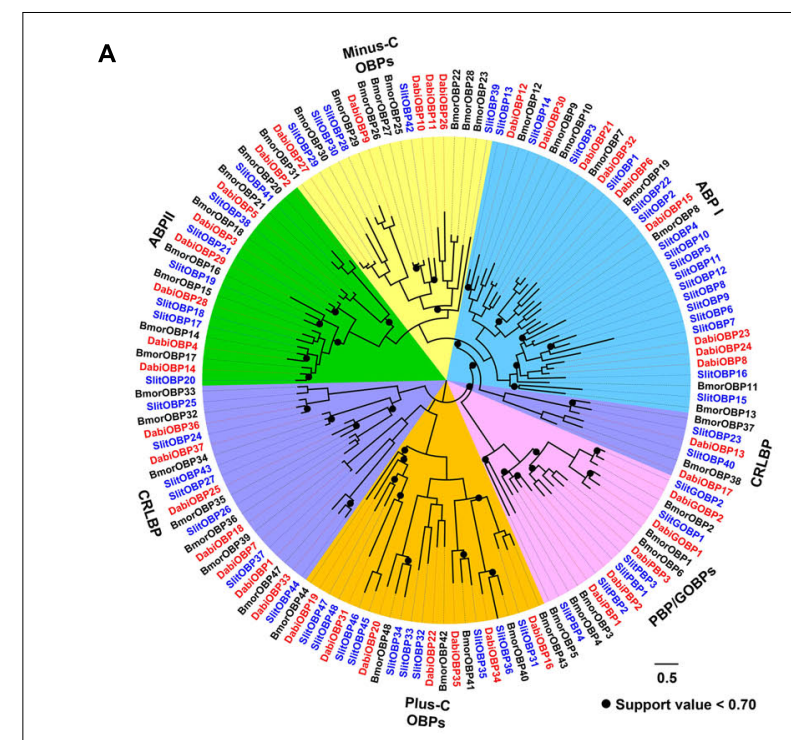

B
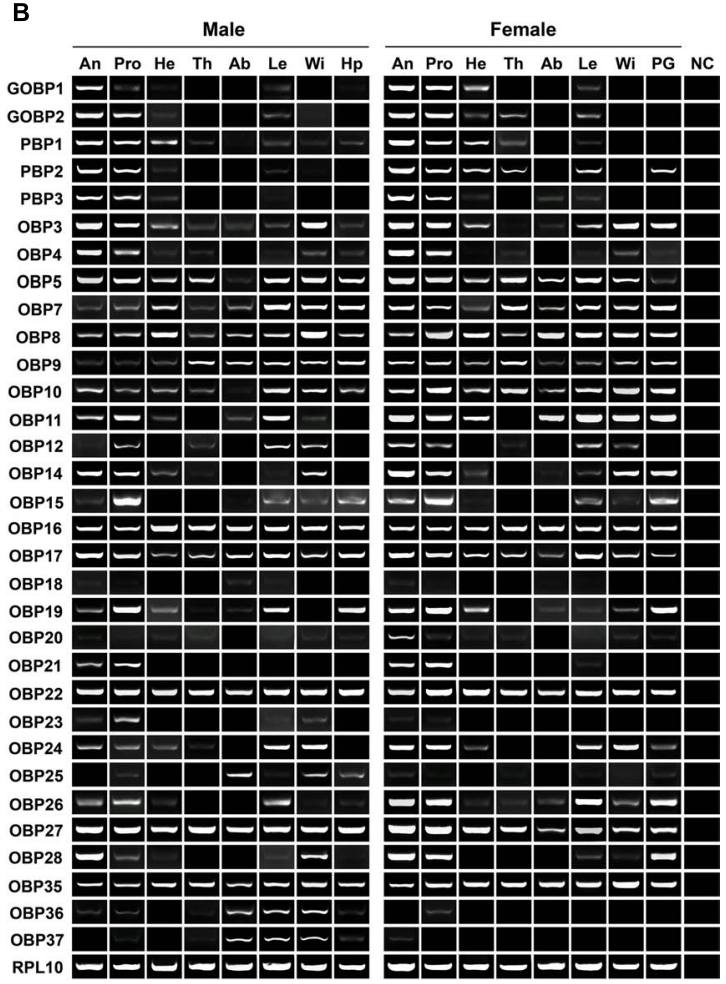

FIGURE 2 | The candidate OBP gene family in D. abietella. (A) The phylogeny of OBPs in S. litura (Slit, blue), D. abietella (Dabi, red) and B. mori (Bmor, black). According to the classification system of OBPs in Lepidoptera, DabiOBPs clustered into six subfamilies. (B) Expression profiles of DabiOBPs in different tissues of both sexes from $D$. abietella. A reference gene, DabiRPL10, was used to check the quality and quantity of cDNA templates. $\mathrm{NC}$, negative control using sterile water as the template. The full names of tissues are listed in Table $\mathbf{1 .}$

half of the genes were enriched in antennae, with DabiPBP1 showing the highest values in males (FPKM $=24511.21)$ (Supplementary Table 4), suggesting their olfactory roles involved in the reception of sex pheromones and plant odorants. 
Some genes (DabiOBP11, OBP15, OBP19, and OBP31) were primarily expressed in gustatory organs such as proboscises and legs (Supplementary Table 4), possibly associated with taste reception as implied in previous studies (Guo et al., 2018; Koutroumpa et al., 2021). Intriguingly, 5 DabiOBPs (DabiOBP9, OBP18, OBP25, OBP36, and OBP37) had obviously high expression in male abdomens (FPKM > 13) but very low levels in females (FPKM < 1) (Supplementary Table 4). As indicated in S. litura, a number of SlitOBPs were abundantly presented in male reproductive tissues (Xiao et al., 2021). Thus, the 5 DabiOBPs may be candidate reproductive-related genes for modulating female or male reproductive-associated behaviors. On the other hand, some DabiOBPs appeared to have sex-biased expression in the antennae, for example, DabiPBP1 had 10.25-fold higher transcription in males compared to females, DabiOBP 19 and OBP31 transcription was female-biased with 17.69-fold and 21.53-fold higher than males, respectively (Supplementary Table 4).

To validate the results of RNA-Seq, we employed RT-PCR to construct the expression profiles of 32 DabiOBPs in 16 tissues of both sexes. Among them, the expression of all the genes appeared to be detectable in the antennae, but 5 genes (DabiOBP18, $O B P 23, O B P 25, O B P 36$, and $O B P 37)$ exhibited extremely weak bands. Interestingly, most of the genes were also transcribed in the proboscises. In addition, a number of DabiOBPs were expressed in non-chemosensory tissues (Figure 2B). Combining RNA-Seq and RT-PCR results, it was found that DabiOBPs were mainly transcribed in the antennae (female: 36 and male: 34) and proboscises (female: 34 and male: 35 ). In 14 other tissues, a comparable number of $D a b i O B P$ genes were obtained, ranging from 15 in female thoraxes and abdomens to 28 in male legs (Table 2). These results well evidenced the presence of DabiOBPs in tissues, suggestive of their functional diversification beyond olfaction.

TABLE 2 | Summary of chemosensory genes expressed in various tissues of D. abietella (FPKM > 1 or RT-PCR and qPCR support).

\begin{tabular}{|c|c|c|c|c|c|c|c|}
\hline $\begin{array}{l}\text { Gene } \\
\text { tissue }\end{array}$ & OBP & CSP & OR & GR & IR & SNMP & Total \\
\hline FA & 36 & 19 & 65 & 6 & 24 & 2 & 152 \\
\hline MA & 34 & 15 & 68 & 5 & 18 & 2 & 142 \\
\hline FPro & 34 & 18 & 31 & 19 & 12 & 2 & 116 \\
\hline MPro & 35 & 18 & 30 & 15 & 9 & 2 & 109 \\
\hline $\mathrm{FH}$ & 24 & 14 & 3 & 2 & 4 & 1 & 48 \\
\hline $\mathrm{MH}$ & 26 & 14 & 3 & 2 & 1 & 1 & 47 \\
\hline FT & 15 & 19 & 6 & 4 & 6 & 2 & 52 \\
\hline MT & 16 & 17 & 5 & 3 & 2 & 2 & 45 \\
\hline FAb & 15 & 16 & 5 & 3 & 2 & 2 & 43 \\
\hline MAb & 17 & 15 & 5 & 4 & 7 & 2 & 50 \\
\hline $\mathrm{FL}$ & 27 & 20 & 3 & 2 & 0 & 1 & 53 \\
\hline $\mathrm{ML}$ & 28 & 20 & 3 & 1 & 6 & 1 & 59 \\
\hline FW & 21 & 17 & 0 & 0 & 0 & 1 & 39 \\
\hline MW & 26 & 19 & 2 & 0 & 1 & 1 & 49 \\
\hline FPG & 22 & 18 & 3 & 6 & 2 & 2 & 53 \\
\hline $\mathrm{MHp}$ & 20 & 18 & 4 & 2 & 7 & 1 & 52 \\
\hline
\end{tabular}

The full names of tissues are seen in Table 1.

\section{Phylogenetic and Expression Profiling Analysis of Dioryctria abietella Chemosensory Proteins}

With 67 CSP protein sequences from B. mori, D. abietella, and S. litura, we inferred the maximum-likelihood phylogeny of CSPs. A high degree of conservation of CSPs among three species was obtained, with 14 orthologous clades (1:1:1) sharing over $50 \%$ average amino acid identities among orthologs (Figure 3A). Compared with the numbers of CSPs in other lepidopterans annotated in the genomes (Gong et al., 2007; Gouin et al., 2017; Pearce et al., 2017), our current transcriptome may identify most, if not all, of the CSP gene family in D. abietella, coupled with phylogenetic analyses of CSPs in the three moths (Figure 3A).

Combining FPKM and RT-PCR approaches, the expression profiles of 23 DabiCSPs were determined. In line with those from other moths (Gong et al., 2007; Xiao et al., 2021), DabiCSPs were broadly expressed in various tissues, and none of the tissue-specific genes were found (Figure 3B). In particular, some of them displayed a very high transcription in each tissue (FPKM > 180), such as DabiCSP5, CSP9, and CSP13. However, DabiCSP11 and CSP21 appeared to be expressed in some tissues at a low level (FPKM < 2.2) (Supplementary Table 4). Together, female and male legs had the largest number of DabiCSPs among tissues with 20 relatives, whereas each 14 genes were presented in heads of both sexes (Table 2).

\section{Phylogenetic and Expression Profiling Analysis of Dioryctria abietella Odorant Receptors}

Using 160 protein sequences from $D$. abietella, $H$. armigera, and O. furnacalis, we built the maximum-likelihood tree of ORs, rooted with a highly conserved Orco clade across insects (Vosshall and Hansson, 2011). Seventy-two DabiORs excluding 3 short DabiORs ( $<200$ amino acids, DabiOR68, OR69, and OR74) were phylogenetically split into various small clades. In the tree, 10 DabiORs clustered into a conserved pheromonesensing PR clade as previously defined (Krieger et al., 2004; Zhang and Löfstedt, 2015), and thus were identified as candidate DabiPRs in D. abietella (Figure 4A). In addition, Bastin-Héline et al. (2019) recently described a novel PR lineage, which was not close to this classical PR clade in phylogeny. To check whether DabiORs clustered into this novel clade, we reconstructed the tree of DabiORs, together with $H$. armigera and $S$. littoralis PRs, and novel PRs identified in a previous study (Bastin-Héline et al., 2019). As a result, DabiOR4 were presented in this novel clade and shared $39.29 \%$ amino acid identity to BmorOR30 in B. mori (Supplementary Figure 4). Therefore, this DabiOR4 gene might be also a PR candidate for the detection of sex pheromones in $D$. abietella. In our phylogenetic analysis, it was noticed that DabiOR23 was homologous to HarmOR42 in H. armigera, with $71.72 \%$ amino acid identities (Figure $\mathbf{4 A}$ ). In this conserved monophylogenetic group including HarmOR42, a recent study indicated that most members of this group, at least 12 orthologous ORs functionally studied, could detect phenylacetaldehyde, a floral volatile common to flowering plants 
A

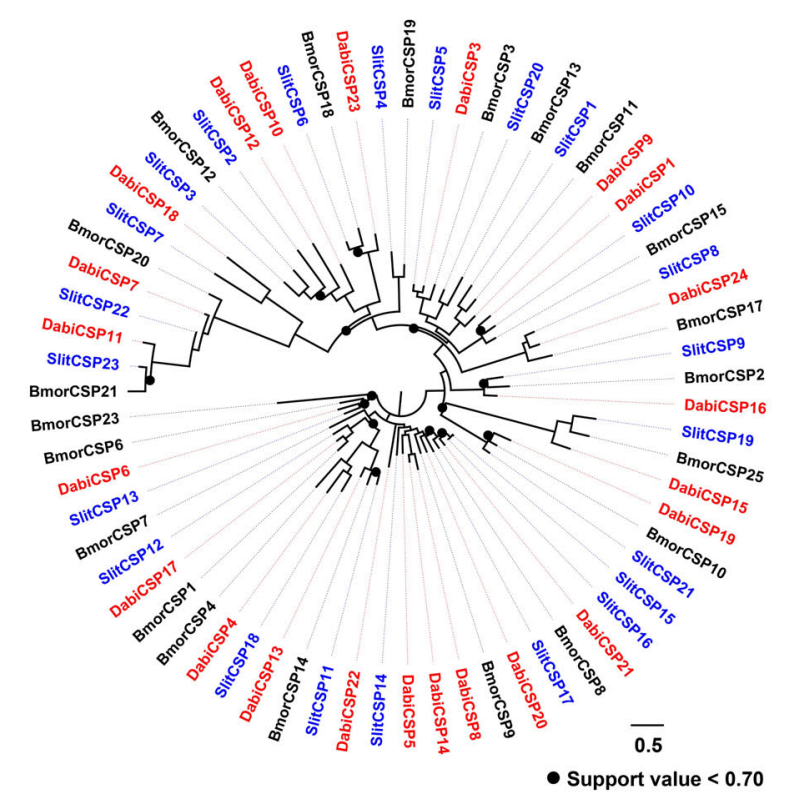

B

Male Female

\begin{tabular}{|c|c|c|c|c|c|c|c|c|c|c|c|c|c|c|c|c|c|}
\hline & An & Pro & $\mathrm{He}$ & Th & $A b$ & Le & Wi & $\mathrm{Hp}$ & An & Pro & $\mathrm{He}$ & Th & $A b$ & Le & Wi & PG & NC \\
\hline CSP1 & & & - & & & $\approx$ & - & & $\exists$ & 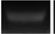 & & - & & $=$ & & & \\
\hline CSP3 & & $\sim$ & - & $=$ & $\Longrightarrow$ & - & - & & & - & $=$ & إس & 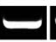 & $=$ & - & - & \\
\hline CSP4 & & & & & & & & & & 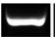 & & & & & & - & \\
\hline CSP5 & & & & D & - & 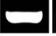 & & & & 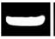 & -1 & & & & 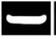 & $\longrightarrow$ & \\
\hline CSP6 & & $=$ & $=$ & - & - & - & 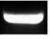 & & 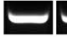 & $\square$ & - & 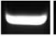 & $=$ & & $\square$ & - & \\
\hline CSP7 & & $=$ & $\sim$ & 工 & $=$ & 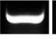 & 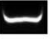 & & - & - & $\sim$ & 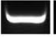 & & - & $\approx$ & - & \\
\hline CSP8 & & 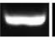 & & & 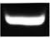 & 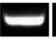 & - & & $=$ & $\longrightarrow$ & - & - & = & $=$ & - & - & \\
\hline CSP9 & & - & 一 & - & - & -1 & 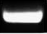 & & $=$ & - & -1 & $=$ & 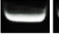 & $=$ & $=$ & - & \\
\hline CSP10 & & & & $=$ & & - & 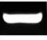 & & & 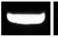 & $=$ & 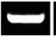 & & & 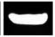 & $\rightarrow$ & \\
\hline CSP11 & & & & $=$ & & & & & - & & & & & & & $\longrightarrow$ & \\
\hline CSP12 & & - & E & - & - & & - & & & $=$ & E & 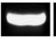 & - & E & $=$ & $\square$ & \\
\hline CSP13 & & - & $=$ & 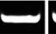 & & 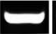 & $=$ & & 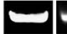 & - & - & 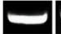 & & & $=$ & $=$ & \\
\hline CSP14 & & & & & & - & - & & & - & & - & & - & - & - & \\
\hline CSP15 & & & & - & $\sim$ & & & & 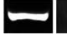 & & & -1 & & 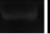 & . & & \\
\hline CSP16 & & & 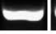 & 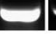 & $\sim$ & 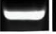 & 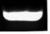 & & - & -1 & 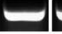 & 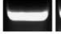 & & 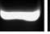 & & 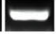 & \\
\hline CSP17 & & $=$ & -1 & - & a & -1 & - & & E & - & - & - & & - & - & ت & \\
\hline CSP18 & & 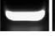 & 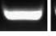 & 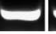 & $=$ & 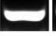 & & & & & & 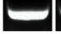 & & & & - & \\
\hline CSP19 & & & 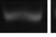 & $=$ & & 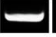 & $=$ & & & $\sigma$ & 0 & & - & - & $=$ & - & \\
\hline CSP20 & & - & -1 & 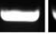 & - & 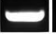 & - & & & -1 & & & & & $=$ & - & \\
\hline CSP21 & & 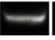 & & & & & & & & & & & & & & & \\
\hline CSP22 & & & & $=$ & & ㄴ. & & & & & & & & & & & \\
\hline CSP23 & & - & & & - & - & - & - & 二 & - & & - & 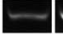 & - & - & 二 & \\
\hline CSP24 & & & & & & $\square$ & - & $=$ & & 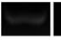 & & $\square$ & & - & ב & & \\
\hline RPL10 & & & & & & & - & & & & & 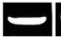 & & & & & \\
\hline
\end{tabular}

FIGURE 3 | The candidate CSP gene family in D. abietella. (A) The phylogeny of CSPs in S. litura (Slit, blue), D. abietella (Dabi, red), and B. mori (Bmor, black).

(B) Expression profiles of DabiCSPs in different tissues of both sexes from D. abietella. A reference gene, DabiRPL10, was used to check the quality and quantity of cDNA templates. NC, negative control using sterile water as the template. The full names of tissues are listed in Table $\mathbf{1 .}$

(Guo et al., 2020). Therefore, we postulated that DabiOR23 may also recognize this compound facilitating the searching of nectar sources.
In the analysis of expression profiles with FPKM values, we found that except for DabiOR70 with unavailable expression data, the majority of DabiORs (67/74) were detected in female or male 


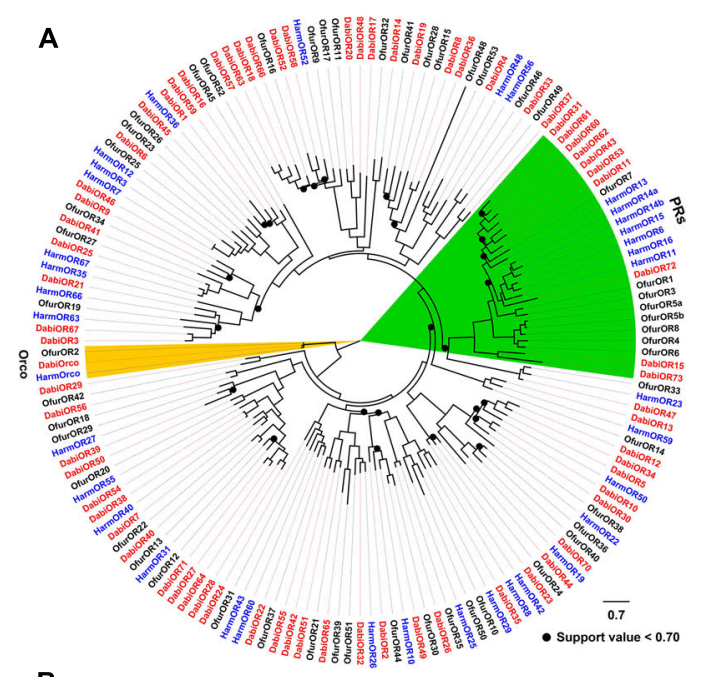

B

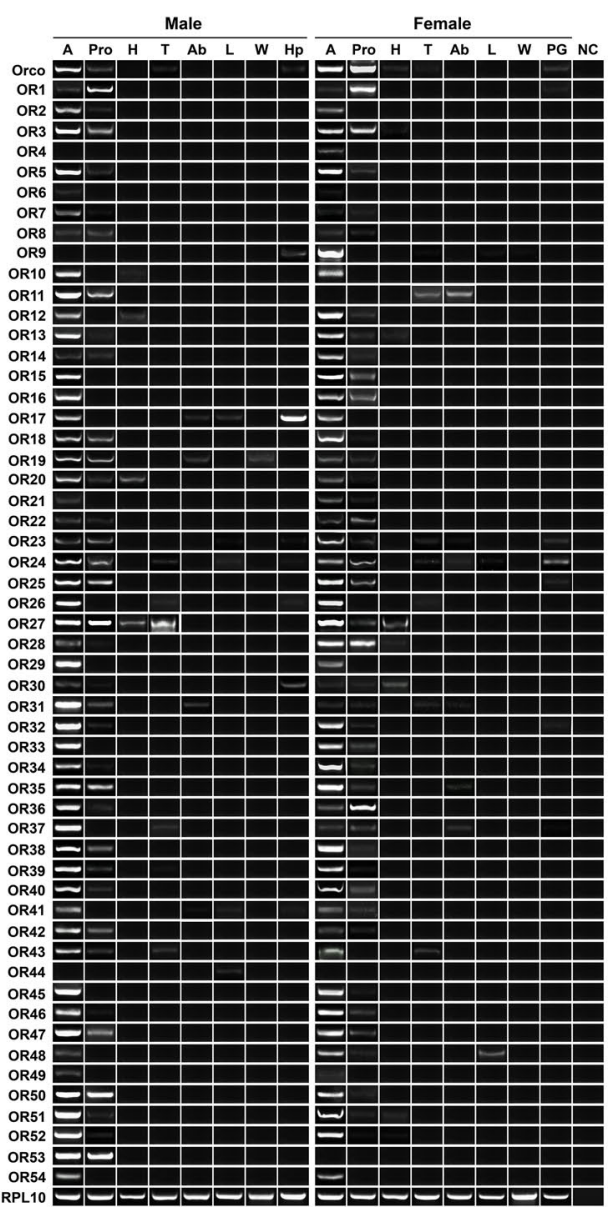

FIGURE 4 | The candidate OR gene family in D. abietella. (A) The phylogeny of ORs in $\mathrm{H}$. armigera (Harm, blue), D. abietella (Dabi, red), and O. furnacalis (Ofur, black). For $H$. armigera ORs, we selected 35 representatives with known functional ligands. A candidate PR subfamily was highlighted and comprised 10 members in $D$. abietella. The tree was rooted with a conserved Orco lineage across insects. (B) Expression profiles of DabiORs in different tissues of both sexes from D. abietella. A reference gene, DabiRPL 10, was used to check the quality and quantity of cDNA templates. NC, negative control using sterile water as the template. The full names of tissues are listed in Table $\mathbf{1}$ antennae $(\mathrm{FPKM}>1)$, in agreement with their olfactory roles. Of these, 26 DabiORs had a relatively high transcription in the antennae (FPKM > 10), with DabiOrco showing the highest expression in males $(\mathrm{FPKM}=250.00)$ or females (FPKM=171.31). In addition, some genes appeared to have sex-biased expression in the antennae of both sexes. For instance, a candidate PR, DabiOR4, was expressed exclusively in female antennae, while DabiOR11, OR53, OR60 and OR72 expression was specific to male antennae (Supplementary Table 4). Interestingly, a certain number of DabiORs were transcribed in the proboscises $($ FPKM > 1) (Supplementary Table 4), a principle feeding and taste organ of adult Lepidoptera. As implied in previous studies, the ORs from other lepidopteran species also had proboscisesdetectable expression (Briscoe et al., 2013; Guo et al., 2018; Koutroumpa et al., 2021). Considering the presence of olfactory sensilla on the proboscises such as sensilla styloconica, sensilla basiconica, and sensilla coeloconica (Faucheux, 2013; Guo et al., 2018; Li et al., 2020), it proposed a possibility that the proboscis may partly bear olfactory roles.

We further employed RT-PCR to examine the expression profiles of 55 full-length DabiORs in different tissues of both sexes. The results showed that the expression of almost all the genes was consistent with RNA-Seq data. Except for DabiOR44 presenting extremely low expression only in male legs, the remaining 54 DabiORs were detected in female and/or male antennae. In addition, at least half of the 54 genes showed the expression in adult proboscises, although most of them were detected at a low level (Figure 4B). In comparison with OBPs and CSPs, most members of the OR gene family had more specific expression in the antennae (up to 65 in females and 68 in males). A considerable number of DabiORs were detected in female and male proboscises, representing 29 and 31 genes, respectively. None of DabiORs were found in female wings (Table 2).

\section{Candidate Pheromone Receptors in Dioryctria abietella}

In the phylogenetic analyses, 11 candidate $D a b i P R$ genes were found in D. abietella. To determine tissue- and sex-specific expression of these genes, we investigated their expression ratios in antennae and other tissues. GPCR analysis revealed that 9 of them were significantly expressed in the antennae relative to other tissues, in which 4 DabiORs (DabiOR4, OR11, OR53, and OR62) transcription was restricted to the antennae and other 5 genes (DabiOR43, OR60, OR61, OR72, and OR73) were detected in the antennal and non-antennal tissues. Of the 11 DabiORs, 4 genes (DabiOR31, OR61, OR62, and OR73) had almost equal expression between female and male antennae, while the remaining 7 genes showed a significantly sex-biased expression in the antennae. Among these, DabiOR11, OR43, OR53, and OR60 were male-biased genes in the antennae, in which DabiOR11 and OR53 previously described as DabiOR41 and OR19, respectively (Xing et al., 2021), had a similar malebiased expression. In contrast to that, DabiOR4, OR15, and OR72 displayed a female-biased expression (Figure 5). It appeared that there were some consistencies between RNA-Seq and qPCR data, that is, similar sex-biased observations for some candidate PRs 


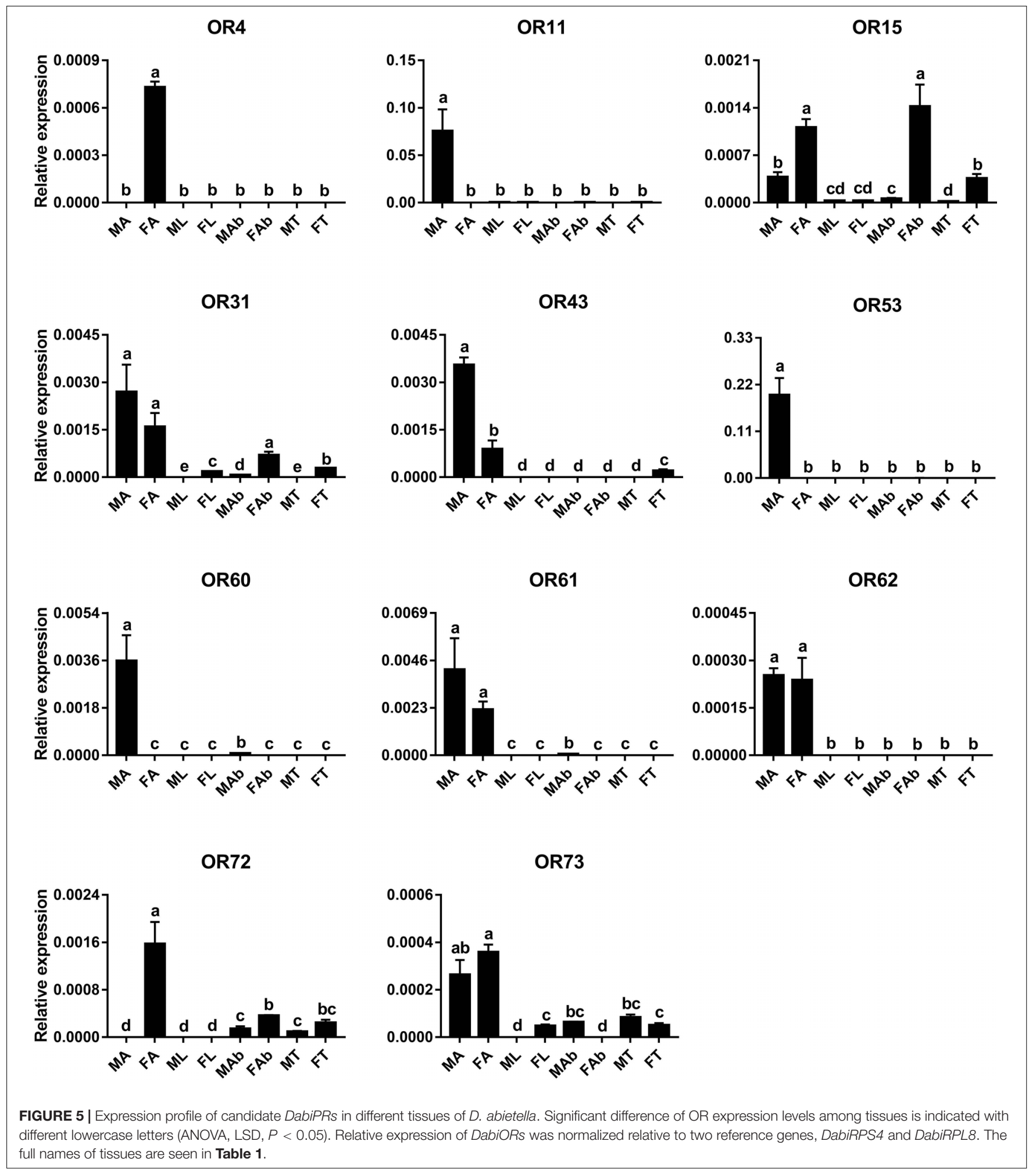

with both FPKM and qPCR results, but some differences were also observed for some genes.

The diverse expression results of DabiPRs in the antennae were different from the PRs in noctuid species, in which the expression of most PR genes was significantly male-biased
(Zhang and Löfstedt, 2015; Bastin-Héline et al., 2019). In comparison with other species in the Pyralidae family, 2 candidate GmelPRs from G. mellonella, GmelOR13 and OR50, were evenly expressed in female and male antennae (Zhao et al., 2019; Jiang et al., 2021). In P. interpunctella, 4 
candidate PintPRs exhibited different sex-biased expression patterns in the antennae, that is, PintOR5 and OR22 were significantly expressed in male antennae, whereas female-biased presence for PintOR7 and OR30 (Jia et al., 2018). In a closely related family Crambidae, a candidate OscaPR gene from Ostrinia scapulalis, OscaOR7, had roughly equal amounts of mRNA in female and male antennae, but failed to respond to female sex pheromones and pheromone orthologs (Miura et al., 2010). In O. furnacalis, OfurOR1 identified as one of the PR members had no or extremely low expression in the antennae (Yang et al., 2015). Similar results about female-biased or equal expression of PRs in the antennae were also observed in Loxostege sticticalis (Wei et al., 2017), Conogethes punctiferalis (Jia et al., 2016), and Chilo suppressalis (Cao et al., 2014). All together, it was noticed that not all candidate PRs of the conserved PR clade in the Pyralidae and Crambidae families had a significantly high expression in male antennae.

\section{Phylogenetic and Expression Profiling Analysis of Dioryctria abietella Gustatory Receptors}

In the phylogenetic inference of GRs, we selected 29 DabiGRs showing more than 200 amino acids to construct the tree, together with 67 B. mori GRs and 15 H. armigera GRs. Following the classification system of GRs in Lepidoptera (Xu, 2020), DabiGRs partitioned into four subfamilies, i.e., $\mathrm{CO}_{2}$, GR43a-like, sugar and bitter receptors comprising 2, 5, 7, and 15 relatives, respectively (Figure 6A). In the two subfamilies of GR43a-like and sugar GRs, the exact numbers of DabiGRs may be larger than we presented here in the tree, as some fragmented proteins ( $<200$ amino acids) in D. abietella were not included. Similar events also occurred in the bitter GRs subfamily. In the $\mathrm{CO}_{2}$ GR1 subclade, our transcriptome did not retrieve the ortholog of GR1 from D. abietella, but its partial sequences were presented in the previous antennal transcriptome (Xing et al., 2021). Given the high sequence identities of GR1 orthologs in this subclade (Xu and Anderson, 2015; Xu, 2020), we attempted to use all 62 DabiGRs to infer the phylogenetic relationships of GRs, coupled with the 67 and 15 GRs separately in B. mori (Guo et al., 2017) and $H$. armigera (Xu and Anderson, 2015). In agreement with the results of the originated tree, the orthologous gene of GR1 was not found from D. abietella (Supplementary Figure 5). This may be due to its extremely low expression in tissues of D. abietella or incorrect assembly.

Expression profiles revealed that all DabiGRs exhibited relatively low or no expression in the sequenced tissues $(0 \leq \mathrm{FPKM}<6)$. Of notice, $10 \mathrm{DabiGRs}$ were not identified from the unigene transcriptome and their FPKM values in tissues were unavailable. Fourteen out of the remaining 52 genes were considerably transcribed in the proboscises of both sexes, including $2 \mathrm{CO}_{2}, 1$ GR43a-like, 2 sugar, 5 bitter and 4 unclassified GRs $(1<$ FPKM $<6)$ (Supplementary Table 4). The proboscises-expressed DabiGRs were well consistent with their gustatory roles, as implied by the GRs in Spodoptera littoralis (Koutroumpa et al., 2021), H. armigera (Guo et al., 2018), and H. melpomene (Briscoe et al., 2013). Notably, FPKMs of only 3
DabiGRs (DabiGR3, GR12, and GR42) in the antennae were above 1 (Supplementary Table 4), largely supported by the observation that few or no GRs were identified in antennal transcriptomes (Supplementary Table 1). As expected, RT-PCR results further supported low expression of DabiGRs in tissues, as well as their extensive presence in the proboscises (Figure 6B). Using the data of FPKM and RT-PCR, we identified 19 and $15 \mathrm{DabiGRs}$ in female and male proboscises, respectively, but no or a few genes were found in other tissues (0-6 relatives) (Table 2 ).

\section{Phylogenetic and Expression Profiling Analysis of Dioryctria abietella Ionotropic Receptors}

We constructed the maximum-likelihood tree of IRs from B. mori, D. abietella, H. armigera, and O. furnacalis, using DabiiGluRs as the outgroup. Phylogenetic analysis allowed us to distinguish the IRs into 29 IR orthologous clades, including one pseudogene group (IR2). Except for the IR31a clade, the remaining clades comprised at least one member of DabilRs. Among the four moth species, most of the IR clades shared a one-to-one orthologous relationship. In particular, each of two clades possessed two gene copies, i.e., IR75q.1 and IR75p/p.2 (Figure 7A). Previously, IR31a genes were lost in several other species, including the Pyralidae family of A. transitella and P. interpunctella, the Cosmopterigidae family of Hyposmocoma kahamanoa and the Plutellidae family of Plutella xylostella (Yin et al., 2021). Therefore, it was possible that D. abietella had lost the ortholog of IR31a during the process of evolution.

In comparison, this divergent IRs (D-IRs) subfamily, especially the IR100 clade, had variable gene numbers ranging from 1 in D. abietella to 9 in O. furnacalis (Figure 7A). As implied in the previous studies, D-IRs members mainly contributed to the difference of IR numbers across the Lepidoptera, and moreover most of them were found to be lowly expressed genes in tissues. In contrast to this subfamily, antennal IRs (A-IRs) and Lepidoptera-specific IRs (LS-IRs) generally had high expression in at least one tissue, and high conservation with single-copy genes among different species (Liu et al., 2018; Zhu et al., 2018; Yin et al., 2021). Accordingly, our study may identify almost all the members of A-IRs and LS-IRs, but missed some D-IRs in D. abietella.

Based on RNA-Seq results, we found that almost all the A-IRs were expressed in the antennae at a considerable level $($ FPKM $>1)$, with the exception of DabiIR40a that appeared to be predominant in the antennae but remarkably low levels (females: 0.79 and males: 0.77). Three IR coreceptors, DabiIR8a, $I R 25 a$ and $I R 76 b$, displayed higher expression in the antennae relative to other tissues. Apart from that, their expression was comparable in the proboscises (FPKM > 1) with that in non-antennal tissues, suggesting that they may be associated with taste function. The common presence of IR coreceptors in the antennae and proboscises was also observed in other A-IRs genes, such as DabiIR21a, IR41a, IR64a, IR75p.1, etc. (Supplementary Table 4), suggesting their dual functional roles in response to odorants and tastants. This expression 


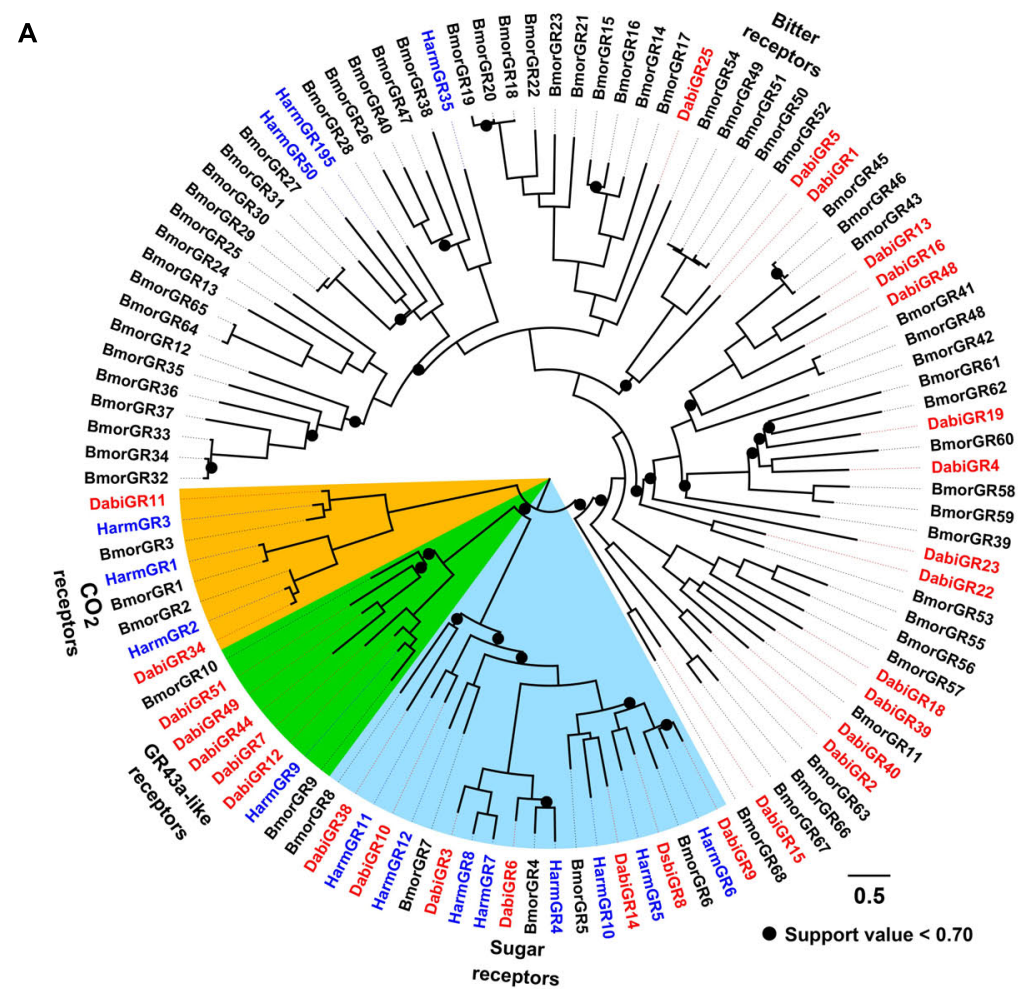

B

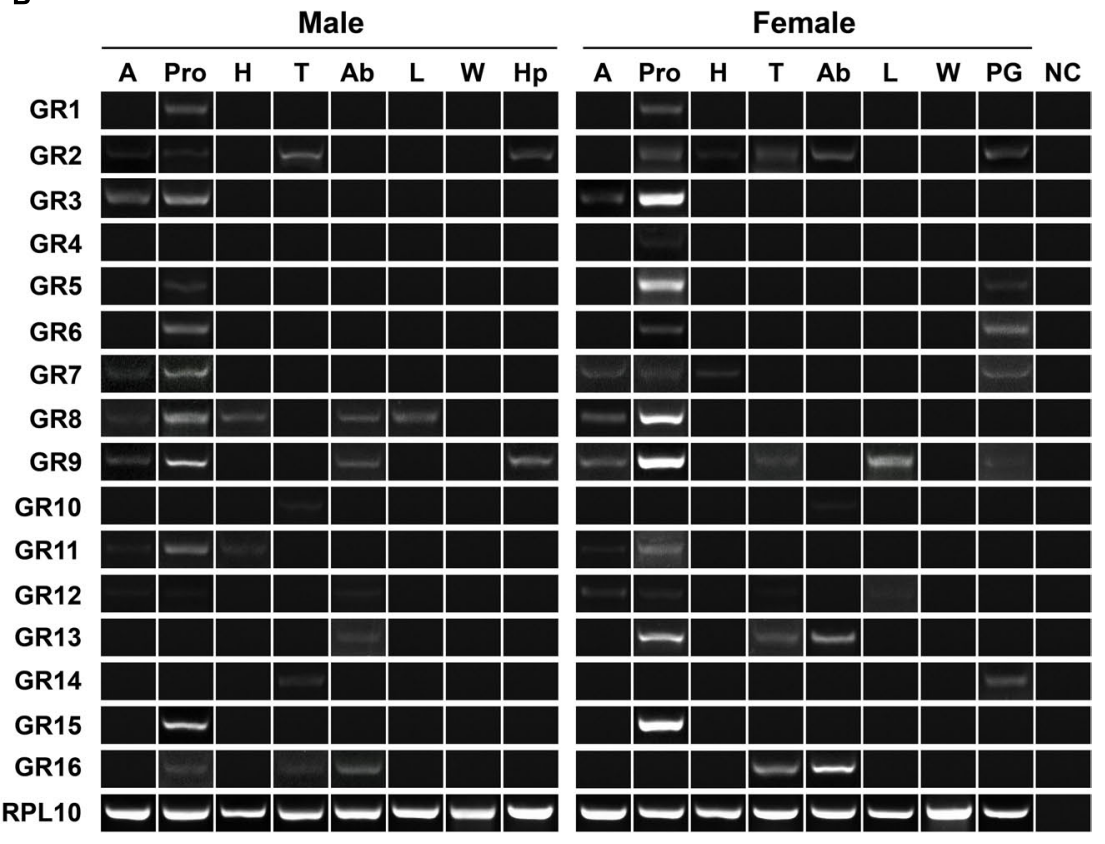

FIGURE 6 | The candidate GR gene family in D. abietella. (A) The phylogeny of GRs in B. mori (Bmor, black), D. abietella (Dabi, red), and H. armigera (Harm, blue). Fifteen HarmGRs were included, representing $3 \mathrm{CO}_{2}, 1 \mathrm{GR} 43$ a-like and 8 sugar GRs, as well as 3 bitter GRs functionally characterized. (B) Expression profiles of candidate DabiGRs in different tissues of both sexes from D. abietella. A reference gene, DabiPRL10, was used to check the quality and quantity of cDNA templates. NC, negative control using sterile water as the template. The full names of tissues are seen in Table 1.

feature of A-IRs presented in olfactory and gustatory tissues was observed in S. litura (Zhu et al., 2018), S. littoralis (Koutroumpa et al., 2021), Papilio xuthus (Yin et al., 2021), and
H. armigera (Liu et al., 2018). In addition, FPKM values of four LS-IRs in the antennae including a pseudogene of DabiIR2 were above 1, but all of the D-IRs subfamily exhibited extremely low 


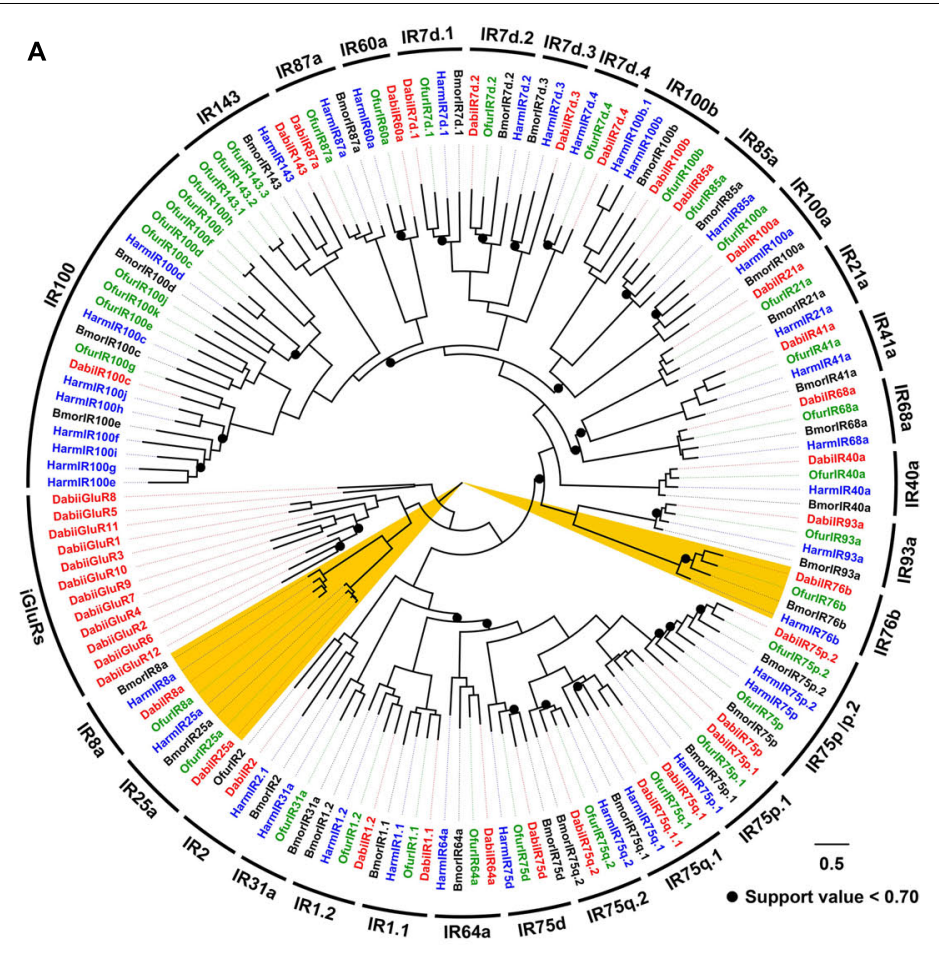

B
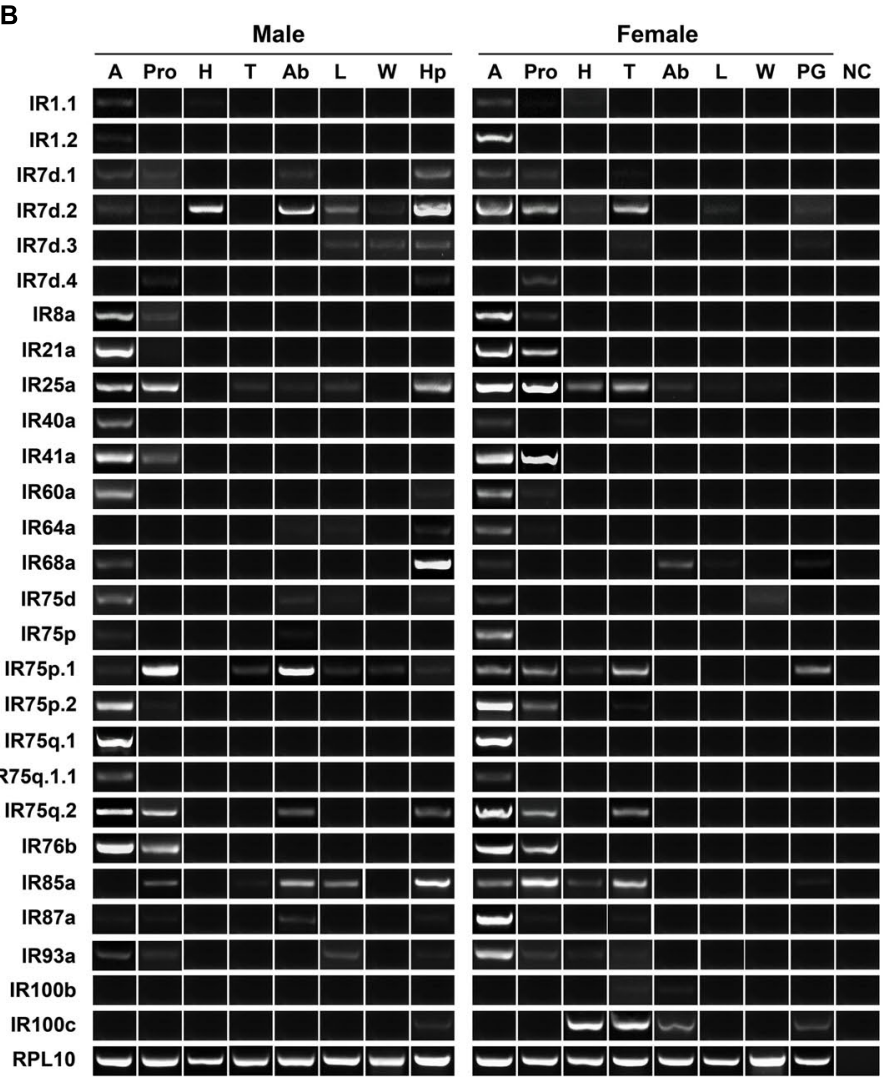

FIGURE 7| The candidate IR gene family in D. abietella. (A) The phylogeny of IRs from B. mori (Bmor, black), D. abietella (Dabi, red), H. armigera (Harm, blue), and O. furnacalis (Ofur, green). According to sequence homology of IRs, members of the IR gene family were grouped into various orthologous clades, with three conserved IR coreceptors (IR8a, IR25a, and IR76b). The tree was rooted with D. abietella iGluRs. (B) Expression profiles of candidate DabilRs in different tissues of both sexes from $D$. abietella. The quality and quantity of cDNA templates were measured by a reference gene, DabiRPL10. NC, negative control using sterile water as the template. The full names of tissues are listed in Table $\mathbf{1 .}$ 
expression levels $(\mathrm{FPKM}<1)$ in the antennae and other tissues (Supplementary Table 4).

Using the RT-PCR method, we further detected the expression profiling map of 31 DabilRs in various tissues, except for DabiIR2. As a result, 29 out of 31 genes were expressed in at least one tissue, with the exception of DabiIR100a and IR143 whose expression was not detected in all tested tissues. We tried to change the primers and annealing temperatures, but the products of DabiIR100a and IR143 failed to be detected. This may reflect extremely low expression of the two genes in tissues. In line with RNA-Seq results, most of DabiIRs were transcribed in the antennae and proboscises. In particular, 2 D-IRs genes also showed a weak expression in the antennae, i.e., DabiIR7d.1 and IR7d.2 (Figure 7B), consistent with that of their orthologs from other moths (Liu et al., 2014, 2018; Yin et al., 2021). Some genes exhibited tissue-specific expression, for example, DabiIR1.1, IR1.2, IR40a, IR60a, IR75q.1, IR75q.1.1, and IR87a in the antennae, and DabiIR85a and IR100d in the proboscises (Figure 7B). All together, the antennae harbored the largest numbers of DabiIRs showing 24 in females and 18 in males, followed by the proboscises with 12 in females and 9 in males (Table 2).

\section{Phylogenetic and Expression Profiling Analysis of Dioryctria abietella Sensory Neuron Membrane Proteins}

Prior to this study, virtually all lepidopteran species with available genomic sequences possess 3 SNMPs, phylogenetically partitioned into three groups with single-copy genes in each
A

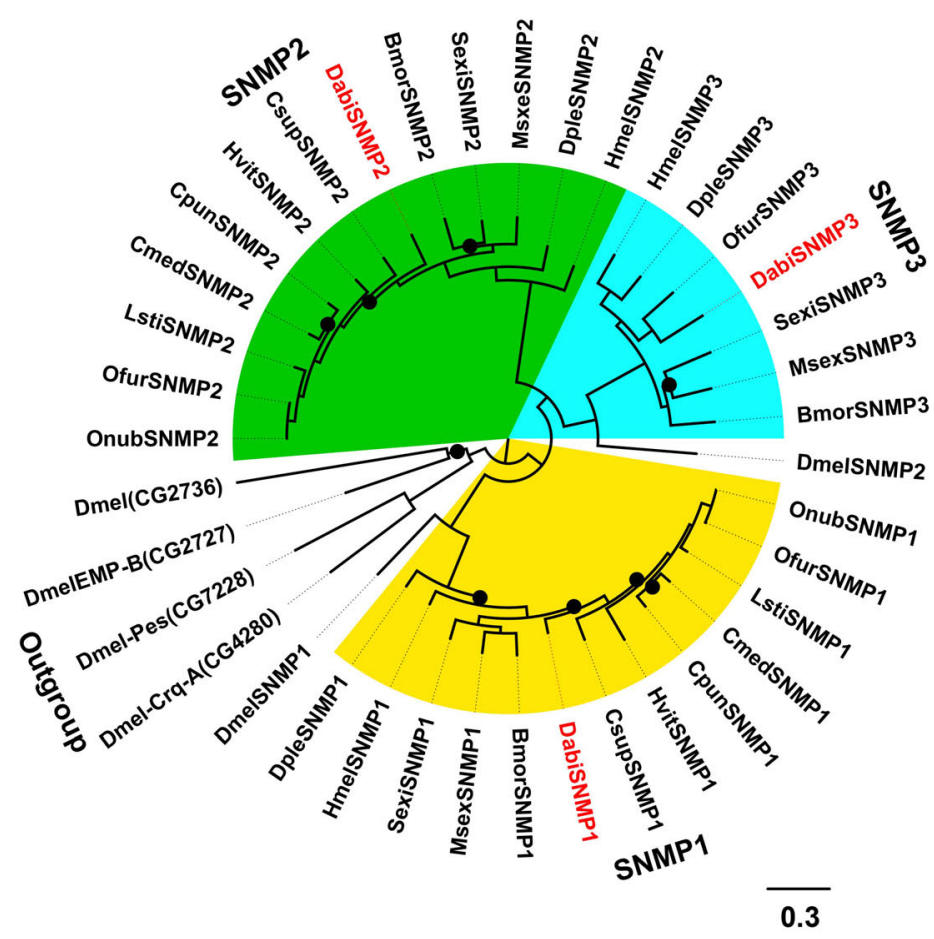

- Support value $<0.70$

B

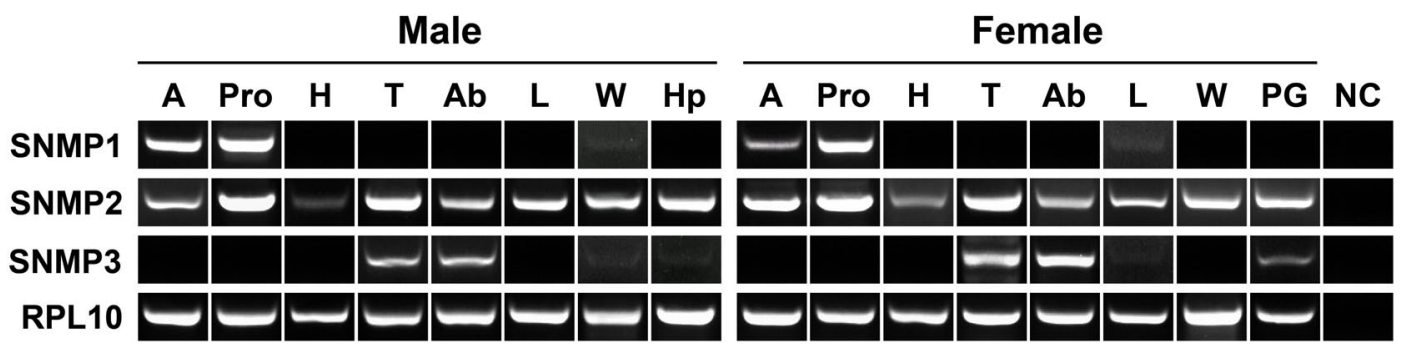

FIGURE 8 | The candidate SNMP gene family in D. abietella. (A) The phylogeny of SNMPs in Lepidoptera and D. melanogaster. DabiSNMPs newly identified in this study are indicated in red. Other members of the CD36 superfamily in D. melanogaster were used to root the tree. (B) Expression profiles of candidate DabiSNMPs in different tissues of $D$. abietella. The quality and quantity of CDNA templates were measured by a reference gene, DabiRPL10. NC, negative control using sterile water as the template. The full names of tissues are seen in Table $\mathbf{1}$. 
group (Zhang et al., 2020). More recently, the SNMP gene repertoire in $A$. yunnanensis was composed of 4 members, representing 1 AyunSNMP1, 2 AyunSNMP2s (AyunSNMP2.1 and SNMP2.2) and 1 AyunSNMP3 (Li G. C. et al., 2021). In agreement with most lepidopteran species, here our transcriptome contained 3 SNMP orthologs that were split into three different clades (Figure 8A).

In the expression profiles of DabiSNMPs, DabiSNMP1 was enriched in the antennae of both sexes, while DabiSNMP2 was broadly presented in all tissues with particularly high expression levels in the antennae, proboscises and wings of female and male moths (FPKM > 500). In contrast to that of 2 DabiSNMPs, DabiSNMP3 expression was not detected in chemosensory-related tissues like antennae, proboscises and legs, but presented primarily in adult abdomens and slightly in adult thoraxes (Supplementary Table 4). RT-PCR results further validated RNA-Seq data of 3 DabiSNMPs. Moreover, DabiSNMP1 appeared to have a higher transcription in male antennae compared to females (Figure 8B), suggesting its putative olfactory roles in the sensing of female sex pheromones in D. abietella, coupled with SNMP1 functions in previous studies (Pregitzer et al., 2014; Liu S. et al., 2020). For the expression of DabiSNMP3 in female and male abdomens (Figure 8B), we suggested that its transcripts may be restricted to midguts of both sexes, as its orthologous genes have been demonstrated to be midgut-specific relatives in B. mori and H. armigera (Zhang et al., 2020; Xu et al., 2021). Taken together, each tissue here studied included at least one SNMP transcript. In particular, 2 SNMP genes were found to have the expression in the antennae and proboscises (DabiSNMP1 and SNMP2), as well as thoraxes and abdomens (DabiSNMP2 and SNMP3) (Table 2).

\section{CONCLUSION}

In this study, we have characterized six chemosensory-related gene families from a destructive forest pest, D. abietella. First, a mixed transcriptome of 16 tissues, including key chemosensory organs of antennae, proboscises and legs, is sequenced and assembled, resulting in the generation of 952,658,466 clean reads and the accumulation of $142.90 \mathrm{G}$ of data. Further, our transcriptome combined with RT-PCR and qPCR analyses identifies 235 genes involved in chemosensation (42 OBPs, 23 CSPs, 75 ORs, 62 GRs, $30 \mathrm{IRs}$, and 3 SNMPs, with an increase of 140 genes), 160 of which are expressed in the antennae (37 OBPs, 20 CSPs, 70 ORs, 6 GRs, 24 IRs, and 3 SNMPs), 137 in the proboscises (36 OBPs, 19 CSPs, 46 ORs, 21 GRs, 13 IRs, and 2 SNMPs), and 67 in the legs (32 OBPs, 21 CSPs, 4 ORs, 3 GRs, 6 $I R s$, and 1 SNMP). Phylogenetic analysis combined with sequence homology allows us to identify 11 candidate DabiPR genes, in which 4 relatives are significantly enriched in male antennae compared to females, and thus are regarded as candidates for the sensation of female sex pheromones in D. abietella. Together, our current work has identified potential molecular targets for sensing sex pheromones and plant-derived compounds that are applied to develop environmentally friendly alternatives for the control of this forest pest.

\section{DATA AVAILABILITY STATEMENT}

The datasets presented in this study can be found in online repositories. The names of the repository/repositories and accession number(s) can be found below: NCBI SRA BioProject, accession no: PRJNA751144.

\section{AUTHOR CONTRIBUTIONS}

N-YL conceived this study and drafted the first manuscript. Z-QW, CW, G-CL, and S-MN performed the laboratory experiments. N-YL, Z-QW, and N-NY analyzed the data. N-YL and Z-QW revised the manuscript. All the authors contributed to the article and approved the submitted version.

\section{FUNDING}

This work was supported by the National Natural Science Foundation of China (31960115), the Yunnan Fundamental Research Project (202001AT070100), and the Yunnan Provincial Support Plan for the Cultivation of High-level Talents-Young Top-notch Talents (YNWR-QNBJ-2019-057).

\section{SUPPLEMENTARY MATERIAL}

The Supplementary Material for this article can be found online at: https://www.frontiersin.org/articles/10.3389/fevo.2021. 748199/full\#supplementary-material

Supplementary Table 1 | Information on chemosensory genes expressed in antennae from 55 moth species.

Supplementary Table 2 | Primers used for expression profiling analyses of chemosensory genes in D. abietella.

Supplementary Table 3 | The CT values and primer amplification efficiencies of 11 DabiORs and 2 reference genes.

Supplementary Table 4 | Information on chemosensory genes from D. abietella.

Supplementary Figure 1 | Raw gel images of candidate chemosensory genes in RT-PCR analyses.

Supplementary Figure 2 | The melting curves of 11 DabiORs in qPCR analyses.

Supplementary Figure $\mathbf{3}$ | Transcriptome summary of 16 adult tissues in D. abietella. (A) Length distribution of unigenes and transcripts. (B) Numbers of unigenes annotated into different databases. (C) GO analyses of unigenes with the five most abundant categories for each term. (D) Homology of D. abietella unigenes with those of other species.

Supplementary Figure 4 | The phylogeny of ORs from D. abietella (Dabi) and other lepidopteran species. The tree was built based on the protein sequences derived from members of a novel PR clade of the Lepidoptera (Bastin-Héline et al., 2019) as well as H. armigera (Harm) and S. littoralis (Slitt) PRs, together with a conserved Orco lineage used to root the tree. D. abietella OR4 clustered into this novel PR clade and was identified as a novel PR candidate.

Supplementary Figure 5 | The phylogeny of 144 GRs in B. mori (Bmor, black), D. abietella (Dabi, red), and $H$. armigera (Harm, blue). Three conserved clades $\left(\mathrm{CO}_{2}\right.$, GR43a-like and sugar receptors) are highlighted with color patterns. 


\section{REFERENCES}

Agnihotri, A. R., Roy, A. A., and Joshi, R. S. (2016). Gustatory receptors in Lepidoptera: chemosensation and beyond. Insect Mol. Biol. 25, 519-529. doi: 10.1111/imb.12246

Andersson, M. N., Keeling, C. I., and Mitchell, R. F. (2019). Genomic content of chemosensory genes correlates with host range in wood-boring beetles (Dendroctonus ponderosae, Agrilus planipennis, and Anoplophora glabripennis). BMC Genomics 20:690. doi: 10.1186/s12864-019-6054-x

Auer, T. O., Khallaf, M. A., Silbering, A. F., Zappia, G., Ellis, K., ÁlvarezOcaña, R., et al. (2020). Olfactory receptor and circuit evolution promote host specialization. Nature 579, 402-408. doi: 10.1038/s41586-020-2073-7

Bastin-Héline, L., de Fouchier, A., Cao, S., Koutroumpa, F., Caballero-Vidal, G., Robakiewicz, S., et al. (2019). A novel lineage of candidate pheromone receptors for sex communication in moths. eLife 8:e49826. doi: 10.7554/eLife.4 9826

Bengtsson, J. M., Trona, F., Montagné, N., Anfora, G., Ignell, R., Witzgall, P., et al. (2012). Putative chemosensory receptors of the codling moth, Cydia pomonella, identified by antennal transcriptome analysis. PLoS One 7:e31620. doi: 10.1371/journal.pone.0031620

Benton, R., Vannice, K. S., Gomez-Diaz, C., and Vosshall, L. B. (2009). Variant ionotropic glutamate receptors as chemosensory receptors in Drosophila. Cell 136, 149-162. doi: 10.1016/j.cell.2008.12.001

Briscoe, A. D., Macias-Munoz, A., Kozak, K. M., Walters, J. R., Yuan, F., Jamie, G. A., et al. (2013). Female behaviour drives expression and evolution of gustatory receptors in butterflies. PLoS Genet. 9:e1003620. doi: 10.1371/journal. pgen. 1003620

Cao, D., Liu, Y., Wei, J., Liao, X., Walker, W. B., Li, J., et al. (2014). Identification of candidate olfactory genes in Chilo suppressalis by antennal transcriptome analysis. Int. J. Biol. Sci. 10, 846-860. doi: 10.7150/ijbs.9297

Chang, X. Q., Nie, X. P., Zhang, Z., Zeng, F. F., Lv, L., Zhang, S., et al. (2017). De novo analysis of the oriental armyworm Mythimna separata antennal transcriptome and expression patterns of odorant-binding proteins. Comp. Biochem. Physiol. D Genomics Proteomics 22, 120-130. doi: 10.1016/j.cbd.2017. 03.001

Cheng, J., Wang, C. Y., Lyu, Z. H., Chen, J. X., Tang, L. P., and Lin, T. (2019). Candidate olfactory genes identified in Heortia vitessoides (Lepidoptera: Crambidae) by antennal transcriptome analysis. Comp. Biochem. Physiol. D Genomics Proteomics 29, 117-130. doi: 10.1016/j.cbd.2018. 11.006

Cheng, T., Wu, J., Wu, Y., Chilukuri, R. V., Huang, L., Yamamoto, K., et al. (2017). Genomic adaptation to polyphagy and insecticides in a major East Asian noctuid pest. Nat. Ecol. Evol. 1, 1747-1756. doi: 10.1038/s41559-017-0 314-4

Clavijo McCormick, A., Grosse-Wilde, E., Wheeler, D., Mescher, M. C., Hansson, B. S., and De Moraes, C. M. (2017). Comparing the expression of olfactionrelated genes in gypsy moth (Lymantria dispar) adult females and larvae from one flightless and two flight-capable populations. Front. Ecol. Evol. 5:115. doi: 10.3389/fevo.2017.00115

Clyne, P. J., Warr, C. G., and Carlson, J. R. (2000). Candidate taste receptors in Drosophila. Science 287, 1830-1834. doi: 10.1126/science.287.545 9.1830

Clyne, P. J., Warr, C. G., Freeman, M. R., Lessing, D., Kim, J., and Carlson, J. R. (1999). A novel family of divergent seven-transmembrane proteins: candidate odorant receptors in Drosophila. Neuron 22, 327-338. doi: 10.1016/s08966273(00)81093-4

Corcoran, J. A., Jordan, M. D., Thrimawithana, A. H., Crowhurst, R. N., and Newcomb, R. D. (2015). The peripheral olfactory repertoire of the lightbrown apple moth Epiphyas postvittana. PLoS One 10:e0128596. doi: 10.1371/journal. pone.0128596

Croset, V., Rytz, R., Cummins, S. F., Budd, A., Brawand, D., Kaessmann, H., et al. (2010). Ancient protostome origin of chemosensory ionotropic glutamate receptors and the evolution of insect taste and olfaction. PLoS Genet. 6:e1001064. doi: 10.1371/journal.pgen.1001064

Cury, K. M., Prud'homme, B., and Gompel, N. (2019). A short guide to insect oviposition: when, where and how to lay an egg. J. Neurogenet. 33, 75-89. doi: 10.1080/01677063.2019.1586898
Davidson, N. M., and Oshlack, A. (2014). Corset: enabling differential gene expression analysis for de novoassembled transcriptomes. Genome Biol. 15:410. doi: 10.1186/s13059-014-0410-6

de Fouchier, A., Walker, W. B., Montagné, N., Steiner, C., Binyameen, M., Schlyter, F., et al. (2017). Functional evolution of Lepidoptera olfactory receptors revealed by deorphanization of a moth repertoire. Nat. Commun. 8:15709. doi: $10.1038 /$ ncomms15709

Dong, J., Song, Y., Li, W., Shi, J., and Wang, Z. (2016). Identification of putative chemosensory receptor genes from the Athetis dissimilis antennal transcriptome. PLoS One 11:e0147768. doi: 10.1371/journal.pone.01 47768

Du, L., Zhao, X., Liang, X., Gao, X., Liu, Y., and Wang, G. (2018). Identification of candidate chemosensory genes in Mythimna separata by transcriptomic analysis. BMC Genomics 19:518. doi: 10.1186/s12864-018-4898-0

Engsontia, P., Sangket, U., Chotigeat, W., and Satasook, C. (2014). Molecular evolution of the odorant and gustatory receptor genes in lepidopteran insects: implications for their adaptation and speciation. J. Mol. Evol. 79, 21-39. doi: 10.1007/s00239-014-9633-0

Enjin, A., Zaharieva, E. E., Frank, D. D., Mansourian, S., Suh, G. S., Gallio, M., et al. (2016). Humidity sensing in Drosophila. Curr. Biol. 26, 1352-1358. doi: 10.1016/j.cub.2016.03.049

Faucheux, M. J. (2013). Sensillum types on the proboscis of the Lepidoptera: a review. Anna. Soc. Entomol. France 49, 73-90. doi: 10.1080/00379271.2013. 767514

Feng, B., Guo, Q., Zheng, K., Qin, Y., and Du, Y. (2017). Antennal transcriptome analysis of the piercing moth Oraesia emarginata (Lepidoptera: Noctuidae). PLoS One 12:e0179433. doi: 10.1371/journal.pone.0179433

Feng, B., Lin, X., Zheng, K., Qian, K., Chang, Y., and Du, Y. (2015). Transcriptome and expression profiling analysis link patterns of gene expression to antennal responses in Spodoptera litura. BMC Genomics 16:269. doi: 10.1186/s12864015-1375-x

Ferguson, S. T., Ray, A., and Zwiebel, L. J. (2021). “16 - Olfactory genomics of eusociality within the Hymenoptera," in Insect Pheromone Biochemistry and Molecular Biology (Second Edition), eds G. J. Blomquist and R. G. Vogt (London: Academic Press), 507-546. doi: 10.1016/B978-0-12-819628-1.0 0016-X

Fleischer, J., and Krieger, J. (2021). "12 - Molecular mechanisms of pheromone detection," in Insect Pheromone Biochemistry and Molecular Biology (Second Edition), eds G. J. Blomquist and R. G. Vogt (London: Academic Press), 355-413. doi: 10.1016/B978-0-12-819628-1.00012-2

Glaser, N., Gallot, A., Legeai, F., Montagné, N., Poivet, E., Harry, M., et al. (2013). Candidate chemosensory genes in the stemborer Sesamia nonagrioides. Int. J. Biol. Sci. 9, 481-495. doi: 10.7150/ijbs.6109

Gong, D. P., Zhang, H. J., Zhao, P., Lin, Y., Xia, Q. Y., and Xiang, Z. H. (2007). Identification and expression pattern of the chemosensory protein gene family in the silkworm, Bombyx mori. Insect Biochem. Mol. Biol. 37, 266-277. doi: 10.1016/j.ibmb.2006.11.012

Gong, D. P., Zhang, H. J., Zhao, P., Xia, Q. Y., and Xiang, Z. H. (2009). The odorant binding protein gene family from the genome of silkworm, Bombyx mori. BMC Genomics 10:332. doi: 10.1186/1471-2164-10-332

Gonzalez, F., Witzgall, P., and Walker, W. B. (2017). Antennal transcriptomes of three tortricid moths reveal putative conserved chemosensory receptors for social and habitat olfactory cues. Sci. Rep. 7:41829. doi: 10.1038/srep4 1829

Gouin, A., Bretaudeau, A., Nam, K., Gimenez, S., Aury, J. M., Duvic, B., et al. (2017). Two genomes of highly polyphagous lepidopteran pests (Spodoptera frugiperda, Noctuidae) with different host-plant ranges. Sci. Rep. 7: 11816. doi: 10.1038/s41598-017-10461-4

Grabherr, M. G., Haas, B. J., Yassour, M., Levin, J. Z., Thompson, D. A., Amit, I., et al. (2011). Full-length transcriptome assembly from RNA-Seq data without a reference genome. Nat. Biotechnol. 29, 644-652.doi:10.1038/nb t.1883

Grosse-Wilde, E., Kuebler, L. S., Bucks, S., Vogel, H., Wicher, D., and Hansson, B. S. (2011). Antennal transcriptome of Manduca sexta. Proc. Natl. Acad. Sci. U.S.A. 108, 7449-7454. doi: 10.1073/pnas.1017963108

Gu, S. H., Sun, L., Yang, R. N., Wu, K. M., Guo, Y. Y., Li, X. C., et al. (2014). Molecular characterization and differential expression of olfactory genes in 
the antennae of the black cutworm moth Agrotis ipsilon. PLoS One 9:e103420. doi: 10.1371/journal.pone.0103420

Gu, T., Huang, K., Tian, S., Sun, Y., Li, H., Chen, C., et al. (2019). Antennal transcriptome analysis and expression profiles of odorant binding proteins in Clostera restitura. Comp. Biochem. Physiol. D Genomics Proteomics 29, 211-220. doi: 10.1016/j.cbd.2018.12.002

Guo, H., Cheng, T., Chen, Z., Jiang, L., Guo, Y., Liu, J., et al. (2017). Expression map of a complete set of gustatory receptor genes in chemosensory organs of Bombyx mori. Insect Biochem. Mol. Biol. 82, 74-82. doi: 10.1016/j.ibmb.2017. 02.001

Guo, M., Chen, Q., Liu, Y., Wang, G., and Han, Z. (2018). Chemoreception of mouthparts: sensilla morphology and discovery of chemosensory genes in proboscis and labial palps of adult Helicoverpa armigera (Lepidoptera: Noctuidae). Front. Physiol. 9:970. doi: 10.3389/fphys.2018.0 0970

Guo, M., Du, L., Chen, Q., Feng, Y., Zhang, J., Zhang, X., et al. (2020). Odorant receptors for detecting flowering plant cues are functionally conserved across moths and butterflies. Mol. Biol. Evol. 38, 1413-1427. doi: 10.1093/molbev/ msaa300

Hou, X. Q., Zhang, D. D., Powell, D., Wang, H. L., Andersson, M. N., and Löfstedt, C. (2021). Ionotropic receptors in the turnip moth Agrotis segetum respond to repellent medium-chain fatty acids. bioRxiv [Preprint] doi: 10.1101/2021.02.25. 432965

Howlett, N., Dauber, K. L., Shukla, A., Morton, B., Glendinning, J. I., Brent, E., et al. (2012). Identification of chemosensory receptor genes in Manduca sexta and knockdown by RNA interference. BMC Genomics 13:211. doi: 10.1186/14712164-13-211

Hu, P., Tao, J., Cui, M., Gao, C., Lu, P., and Luo, Y. (2016). Antennal transcriptome analysis and expression profiles of odorant binding proteins in Eogystia hippophaecolus (Lepidoptera: Cossidae). BMC Genomics 17:651. doi: 10.1186/ s12864-016-3008-4

Jia, X. J., Wang, H. X., Yan, Z. G., Zhang, M. Z., Wei, C. H., Qin, X. C., et al. (2016). Antennal transcriptome and differential expression of olfactory genes in the yellow peach moth, Conogethes punctiferalis (Lepidoptera: Crambidae). Sci. Rep. 6:29067. doi: 10.1038/srep29067

Jia, X., Zhang, X., Liu, H., Wang, R., and Zhang, T. (2018). Identification of chemosensory genes from the antennal transcriptome of Indian meal moth Plodia interpunctella. PLoS One 13:e0189889. doi: 10.1371/journal.pone. 0189889

Jiang, X. C., Liu, S., Jiang, X. Y., Wang, Z. W., Xiao, J. J., Gao, Q., et al. (2021). Identification of olfactory genes from the greater wax moth by antennal transcriptome analysis. Front. Physiol. 12:663040. doi: 10.3389/fphys.2021. 663040

Jiang, X. J., Guo, H., Di, C., Yu, S., Zhu, L., Huang, L. Q., et al. (2014). Sequence similarity and functional comparisons of pheromone receptor orthologs in two closely related Helicoverpa species. Insect Biochem. Mol. Biol. 48, 63-74. doi: 10.1016/j.ibmb.2014.02.010

Kasubuchi, M., Shii, F., Tsuneto, K., Yamagishi, T., Adegawa, S., Endo, H., et al. (2018). Insect taste receptors relevant to host identification by recognition of secondary metabolite patterns of non-host plants. Biochem. Biophys. Res. Commun. 499, 901-906. doi: 10.1016/j.bbrc.2018.04.014

Katoh, K., and Standley, D. M. (2013). MAFFT multiple sequence alignment software version 7: improvements in performance and usability. Mol. Biol. Evol. 30, 772-780. doi: 10.1093/molbev/mst010

Kawahara, A. Y., Plotkin, D., Espeland, M., Meusemann, K., Toussaint, E. F. A., Donath, A., et al. (2019). Phylogenomics reveals the evolutionary timing and pattern of butterflies and moths. Proc. Natl. Acad. Sci. U.S.A. 116, 22657-22663. doi: $10.1073 /$ pnas. 1907847116

Knecht, Z. A., Silbering, A. F., Ni, L., Klein, M., Budelli, G., Bell, R., et al. (2016). Distinct combinations of variant ionotropic glutamate receptors mediate thermosensation and hygrosensation in Drosophila. eLife 5:e17879. doi: 10. 7554/eLife. 17879

Koenig, C., Hirsh, A., Bucks, S., Klinner, C., Vogel, H., Shukla, A., et al. (2015). A reference gene set for chemosensory receptor genes of Manduca sexta. Insect Biochem. Mol. Biol. 66, 51-63. doi: 10.1016/j.ibmb.2015.09.007

Koutroumpa, F. A., Monsempes, C., François, M. C., Severac, D., Montagné, N., Meslin, C., et al. (2021). Description of chemosensory genes in unexplored tissues of the moth Spodoptera littoralis. Front. Ecol. Evol. 9:678277. doi: 10. 3389/fevo.2021.678277

Krieger, J., Gondesen, I., Forstner, M., Gohl, T., Dewer, Y., and Breer, H. (2009). HR11 and HR13 receptor-expressing neurons are housed together in pheromone-responsive Sensilla trichodea of male Heliothis virescens. Chem. Senses 34, 469-477. doi: 10.1093/chemse/bjp012

Krieger, J., Grosse-Wilde, E., Gohl, T., Dewer, Y. M., Raming, K., and Breer, H. (2004). Genes encoding candidate pheromone receptors in a moth (Heliothis virescens). Proc. Natl. Acad. Sci. U.S.A. 101, 11845-11850. doi: 10.1073/pnas. 0403052101

Leal, W. S. (2013). Odorant reception in insects: roles of receptors, binding proteins, and degrading enzymes. Annu. Rev. Entomol. 58, 373-391. doi: 10. 1146/annurev-ento-120811-153635

Li, B., and Dewey, C. N. (2011). RSEM: accurate transcript quantification from RNA-Seq data with or without a reference genome. BMC Bioinformatics 12:323. doi: 10.1186/1471-2105-12-323

Li, G. C., Nuo, S. M., Wang, Z. Q., Yang, A. J., and Liu, N. Y. (2021). Identification and expression profiling of chemosensory membrane protein genes in Achelura yunnanensis (Lepidoptera: Zygaenidae). Comp. Biochem. Physiol. D Genomics Proteomics 40:100876. doi: 10.1016/j.cbd.2021.100876

Li, G. C., Zhao, Y. J., Li, J. L., Lu, G. Y., and Liu, N. Y. (2020). Ultrastructure of sensilla on the antennae, proboscis and tarsi of adult Achelura yunnanensis (Lepidoptera: Zygaenidae). Acta Entomol. Sin. 63, 1385-1398. doi: 10.16380/j. kcxb.2020.11.011

Li, G., Du, J., Li, Y., and Wu, J. (2015). Identification of putative olfactory genes from the oriental fruit moth Grapholita molesta via an antennal transcriptome analysis. PLoS One 10:e0142193. doi: 10.1371/journal.pone.01 42193

Li, L. L., Xu, J. W., Yao, W. C., Yang, H. H., Dewer, Y., Zhang, F., et al. (2021). Chemosensory genes in the head of Spodoptera litura larvae. B. Entomol. Res. 111, 1-10. doi: 10.1017/S0007485321000109

Li, Z. Q., Luo, Z. X., Cai, X. M., Bian, L., Xin, Z. J., Liu, Y., et al. (2017). Chemosensory gene families in Ectropis grisescens and candidates for detection of type-II sex pheromones. Front. Physiol. 8:953. doi: 10.3389/fphys.2017.0 0953

Liu, J., Liu, H., Yi, J., Mao, Y., Li, J., Sun, D., et al. (2021). Transcriptome characterization and expression analysis of chemosensory genes in Chilo sacchariphagus (Lepidoptera Crambidae), a key pest of sugarcane. Front. Physiol. 12:636353. doi: 10.3389/fphys.2021.636353

Liu, N. Y., Xu, W., Dong, S. L., Zhu, J. Y., Xu, Y. X., and Anderson, A. (2018). Genome-wide analysis of ionotropic receptor gene repertoire in Lepidoptera with an emphasis on its functions of Helicoverpa armigera. Insect Biochem. Mol. Biol. 99, 37-53. doi: 10.1016/j.ibmb.2018.05.005

Liu, N. Y., Xu, W., Papanicolaou, A., Dong, S. L., and Anderson, A. (2014). Identification and characterization of three chemosensory receptor families in the cotton bollworm Helicoverpa armigera. BMC Genomics 15:597. doi: 10. 1186/1471-2164-15-597

Liu, N. Y., Zhang, T., Ye, Z. F., Li, F., and Dong, S. L. (2015). Identification and characterization of candidate chemosensory gene families from Spodoptera exigua developmental transcriptomes. Int. J. Biol. Sci. 11, 1036-1048. doi: 10. 7150/ijbs. 12020

Liu, P., Zhang, X., Meng, R., Liu, C., Li, M., and Zhang, T. (2020). Identification of chemosensory genes from the antennal transcriptome of Semiothisa cinerearia. PLoS One 15:e0237134. doi: 10.1371/journal.pone.0237134

Liu, S., Chang, H., Liu, W., Cui, W., Liu, Y., Wang, Y., et al. (2020). Essential role for SNMP1 in detection of sex pheromones in Helicoverpa armigera. Insect Biochem. Mol. Biol. 127:103485. doi: 10.1016/j.ibmb.2020.1 03485

Liu, X. L., Zhang, J., Yan, Q., Miao, C. L., Han, W. K., Hou, W., et al. (2020). The molecular basis of host selection in a crucifer-specialized moth. Curr. Biol. 30, 4476-4482.e4475. doi: 10.1016/j.cub.2020.08.047

Liu, Y., Gu, S., Zhang, Y., Guo, Y., and Wang, G. (2012). Candidate olfaction genes identified within the Helicoverpa armigera antennal transcriptome. PLoS One 7:e48260. doi: 10.1371/journal.pone.0048260

Liu, Y., Liu, C., Lin, K., and Wang, G. (2013). Functional specificity of sex pheromone receptors in the cotton bollworm Helicoverpa armigera. PLoS One 8:e62094. doi: 10.1371/journal.pone.0062094 
Liu, Y., Liu, H., Wang, H., Huang, T., Liu, B., Yang, B., et al. (2021). Apolygus lucorum genome provides insights into omnivorousness and mesophyll feeding. Mol. Ecol. Resour. 21, 287-300. doi: 10.1111/1755-0998.13253

Llopis-Gimenez, A., Carrasco-Oltra, T., Jacquin-Joly, E., Herrero, S., and Crava, C. M. (2020). Coupling transcriptomics and behaviour to unveil the olfactory system of Spodoptera exigua larvae. J. Chem. Ecol. 46, 1017-1031. doi: 10.1007/ s10886-020-01224-z

Löfstedt, C., Svensson, G. P., Jirle, E. V., Rosenberg, O., Roques, A., and Millar, J. G. (2012). (3Z,6Z,9Z,12Z,15Z)-pentacosapentaene and (9Z,11E)tetradecadienyl acetate: sex pheromone of the spruce coneworm Dioryctria abietella (Lepidoptera: Pyralidae). J. Appl. Entomol. 136, 70-78. doi: 10.1111/ j.1439-0418.2011.01619.x

Löfstedt, C., van der Pers, J. N. C., Löfqvist, J., and Lanne, B. S. (1983). Sex pheromone of the cone pyralid Dioryctria abietella. Entomol. Exp. Appl. 34, 20-26. doi: 10.1111/j.1570-7458.1983.tb03285.x

McKenna, D. D., Shin, S., Ahrens, D., Balke, M., Beza-Beza, C., Clarke, D. J., et al. (2019). The evolution and genomic basis of beetle diversity. Proc. Natl. Acad. Sci. U.S.A. 116, 24729. doi: 10.1073/pnas. 1909655116

Mitchell, R. F., and Andersson, M. N. (2021). "17 - Olfactory genomics of the Coleoptera," in Insect Pheromone Biochemistry and Molecular Biology (Second Edition), eds G. J. Blomquist and R. G. Vogt (London: Academic Press), 547-590. doi: 10.1016/B978-0-12-819628-1.00017-1

Mitchell, R. F., Schneider, T. M., Schwartz, A. M., Andersson, M. N., and McKenna, D. D. (2020). The diversity and evolution of odorant receptors in beetles (Coleoptera). Insect Mol. Biol. 29, 77-91. doi: 10.1111/imb.12611

Miura, N., Nakagawa, T., Touhara, K., and Ishikawa, Y. (2010). Broadly and narrowly tuned odorant receptors are involved in female sex pheromone reception in Ostrinia moths. Insect Biochem. Mol. Biol. 40, 64-73. doi: 10.1016/ j.ibmb.2009.12.011

Montagné, N., Wanner, K., and Jacquin-Joly, E. (2021). "15 - Olfactory genomics within the Lepidoptera," in Insect Pheromone Biochemistry and Molecular Biology (Second Edition), eds G. J. Blomquist and R. G. Vogt (London: Academic Press), 469-505. doi: 10.1016/B978-0-12-819628-1.00015-8

Muller, P. Y., Janovjak, H., Miserez, A. R., and Dobbie, Z. (2002). Processing of gene expression data generated by quantitative real-time RT-PCR. Biotechniques 32, 1372-1374, 1376, 1378-1379.

Ning, C., Yang, K., Xu, M., Huang, L. Q., and Wang, C. Z. (2016). Functional validation of the carbon dioxide receptor in labial palps of Helicoverpa armigera moths. Insect Biochem. Mol. Biol. 73, 12-19. doi: 10.1016/j.ibmb.2016. 04.002

Nozawa, M., and Nei, M. (2007). Evolutionary dynamics of olfactory receptor genes in Drosophila species. Proc. Natl. Acad. Sci. U.S.A. 104, 7122-7127. doi: 10.1073/pnas.0702133104

Obiero, G. F., Pauli, T., Geuverink, E., Veenendaal, R., Niehuis, O., and GroßeWilde, E. (2021). Chemoreceptor diversity in apoid wasps and its reduction during the evolution of the pollen-collecting lifestyle of bees (Hymenoptera: Apoidea). Genome Biol. Evol. 13:evaa269. doi: 10.1093/gbe/evaa269

Ozaki, K., Ryuda, M., Yamada, A., Utoguchi, A., Ishimoto, H., Calas, D., et al. (2011). A gustatory receptor involved in host plant recognition for oviposition of a swallowtail butterfly. Nat. Commun. 2:542. doi: 10.1038/ncomms 1548

Pearce, S. L., Clarke, D. F., East, P. D., Elfekih, S., Gordon, K. H. J., Jermiin, L. S., et al. (2017). Genomic innovations, transcriptional plasticity and gene loss underlying the evolution and divergence of two highly polyphagous and invasive Helicoverpa pest species. BMC Biol. 15:63. doi: 10.1186/s12915-0170402-6

Pelosi, P., Iovinella, I., Zhu, J., Wang, G., and Dani, F. R. (2018). Beyond chemoreception: diverse tasks of soluble olfactory proteins in insects. Biol. Rev. 93, 184-200. doi: 10.1111/brv.12339

Pregitzer, P., Greschista, M., Breer, H., and Krieger, J. (2014). The sensory neurone membrane protein SNMP1 contributes to the sensitivity of a pheromone detection system. Insect Mol. Biol. 23, 733-742. doi: 10.1111/imb.12119

Price, M. N., Dehal, P. S., and Arkin, A. P. (2010). FastTree 2 - approximately maximum-likelihood trees for large alignments. PLoS One 5:e9490. doi: 10. 1371/journal.pone.0009490

Qiu, C. Z., Zhou, Q. Z., Liu, T. T., Fang, S. M., Wang, Y. W., Fang, X., et al. (2018). Evidence of peripheral olfactory impairment in the domestic silkworms: insight from the comparative transcriptome and population genetics. BMC Genomics 19:788. doi: 10.1186/s12864-018-5172-1

Qiu, L., He, L., Tan, X., Zhang, Z., Wang, Y., Li, X., et al. (2020). Identification and phylogenetics of Spodoptera frugiperda chemosensory proteins based on antennal transcriptome data. Comp. Biochem. Physiol. D Genomics Proteomics 34:100680. doi: 10.1016/j.cbd.2020.100680

Robertson, H. M. (2019). Molecular evolution of the major Arthropod chemoreceptor gene families. Annu. Rev. Entomol. 64, 227-242. doi: 10.1146/ annurev-ento-020117-043322

Rojas, V., Jimenez, H., Palma-Millanao, R., Gonzalez-Gonzalez, A., Machuca, J., Godoy, R., et al. (2018). Analysis of the grapevine moth Lobesia botrana antennal transcriptome and expression of odorant-binding and chemosensory proteins. Comp. Biochem. Physiol. D Genomics Proteomics 27, 1-12. doi: 10. 1016/j.cbd.2018.04.003

Rosenberg, O., and Weslien, J. (2005). Assessment of cone-damaging insects in a Swedish spruce seed orchard and the efficacy of large-scale application of Bacillus thuringiensis variety aizawai $\times$ kurstaki against lepidopterans. J. Econ. Entomol. 98, 402-408. doi: 10.1093/jee/98.2.402

Rytz, R., Croset, V., and Benton, R. (2013). Ionotropic Receptors (IRs): chemosensory ionotropic glutamate receptors in Drosophila and beyond. Insect Biochem. Mol. Biol. 43, 888-897. doi: 10.1016/j.ibmb.2013.02.007

Silbering, A. F., Rytz, R., Grosjean, Y., Abuin, L., Ramdya, P., Jefferis, G. S., et al. (2011). Complementary function and integrated wiring of the evolutionarily distinct Drosophila olfactory subsystems. J. Neurosci. 31, 13357-13375. doi: 10.1523/JNEUROSCI.2360-11.2011

Simon, P. (2003). Q-Gene: processing quantitative real-time RT-PCR data. Bioinformatics 19, 1439-1440. doi: 10.1093/bioinformatics/btg157

Smadja, C., Shi, P., Butlin, R. K., and Robertson, H. M. (2009). Large gene family expansions and adaptive evolution for odorant and gustatory receptors in the pea aphid, Acyrthosiphon pisum. Mol. Biol. Evol. 26, 2073-2086. doi: 10.1093/ molbev/msp116

Song, Y., Li, J., Zhou, Y., and Zhang, T. (2020). Advances in research and control of Dioryctria pests in China. For. Pest Dis. 39, 29-41. doi: 10.19688/j.cnki. issn1671-0886.20200040

Steinwender, B., Thrimawithana, A. H., Crowhurst, R. N., and Newcomb, R. D. (2015). Pheromone receptor evolution in the cryptic leafroller species, Ctenopseustis obliquana and C. herana. J. Mol. Evol. 80, 42-56. doi: 10.1007/ s00239-014-9650-z

Steinwender, B., Thrimawithana, A. H., Crowhurst, R., and Newcomb, R. D. (2016). Odorant receptors of the new zealand endemic leafroller moth species Planotortrix octo and P. excessana. PLoS One 11:e0152147. doi: 10.1371/journal. pone. 0152147

Stewart, S., Koh, T. W., Ghosh, A. C., and Carlson, J. R. (2015). Candidate ionotropic taste receptors in the Drosophila larva. Proc. Natl. Acad. Sci. U.S.A. 112, 4195-4201. doi: 10.1073/pnas.1503292112

Sun, H., Song, Y., Du, J., Wang, X., and Cheng, Z. (2016). Identification and tissue distribution of chemosensory protein and odorant binding protein genes in Athetis dissimilis (Lepidoptera: Noctuidae). Appl. Entomol. Zool. 51, 409-420. doi: 10.1007/s13355-016-0413-8

Sun, Y. L., Dong, J. F., Gu, N., and Wang, S. L. (2020). Identification of candidate chemosensory receptors in the antennae of the variegated cutworm, Peridroma saucia Hübner, based on a transcriptome analysis. Front. Physiol. 11:39. doi: $10.3389 /$ fphys.2020.00039

Tang, X., Gao, T., Lu, J., Hong, D., Tong, X., and Ren, Y. (2020). Relationship between volatile compounds of Picea likiangensis var. linzhiensis cone and host selection of Dioryctria abietella. Arch. Insect Biochem. Physiol. 105:e21733. doi: 10.1002/arch.21733

Tian, Z., Sun, L., Li, Y., Quan, L., Zhang, H., Yan, W., et al. (2018). Antennal transcriptome analysis of the chemosensory gene families in Carposina sasakii (Lepidoptera: Carposinidae). BMC Genomics 19:544. doi: 10.1186/s12864-0184900-x

Trapnell, C., Williams, B. A., Pertea, G., Mortazavi, A., Kwan, G., van Baren, M. J., et al. (2010). Transcript assembly and quantification by RNA-Seq reveals unannotated transcripts and isoform switching during cell differentiation. Nat. Biotechnol. 28, 511-515. doi: 10.1038/nbt.1621

Vogt, R. G., Große-Wilde, E., and Zhou, J. J. (2015). The Lepidoptera odorant binding protein gene family: gene gain and loss within the GOBP/PBP complex 
of moths and butterflies. Insect Biochem. Mol. Biol. 62, 142-153. doi: 10.1016/j. ibmb.2015.03.003

Vogt, R. G., Miller, N. E., Litvack, R., Fandino, R. A., Sparks, J., Staples, J., et al. (2009). The insect SNMP gene family. Insect Biochem. Mol. Biol. 39, 448-456. doi: 10.1016/j.ibmb.2009.03.007

Vosshall, L. B., and Hansson, B. S. (2011). A unified nomenclature system for the insect olfactory coreceptor. Chem. Senses 36, 497-498. doi: 10.1093/chemse/ bjr022

Walker, W. B. III, Roy, A., Anderson, P., Schlyter, F., Hansson, B. S., and Larsson, M. C. (2019). Transcriptome analysis of gene families involved in chemosensory function in Spodoptera littoralis (Lepidoptera: Noctuidae). BMC Genomics 20:428. doi: 10.1186/s12864-019-5815-x

Walker, W. B., Gonzalez, F., Garczynski, S. F., and Witzgall, P. (2016). The chemosensory receptors of codling moth Cydia pomonella-expression in larvae and adults. Sci. Rep. 6:23518. doi: 10.1038/srep23518

Wang, S., Minter, M., Homem, R. A., Michaelson, L. V., Venthur, H., Lim, K. S., et al. (2020). Odorant binding proteins promote flight activity in the migratory insect, Helicoverpa armigera. Mol. Ecol. 29, 3795-3808. doi: 10.1111/mec.1 5556

Wei, H. S., Li, K. B., Zhang, S., Cao, Y. Z., and Yin, J. (2017). Identification of candidate chemosensory genes by transcriptome analysis in Loxostege sticticalis Linnaeus. PLoS One 12:e0174036. doi: 10.1371/journal.pone.0174036

Xiao, H. Y., Li, G. C., Wang, Z. Q., Guo, Y. R., and Liu, N. Y. (2021). Combined transcriptomic, proteomic and genomic analysis identifies reproductive-related proteins and potential modulators of female behaviors in Spodoptera litura. Genomics 113, 1876-1894. doi: 10.1016/j.ygeno.2021.04.006

Xiao, W., Yang, L., Xu, Z., and He, L. (2016). Transcriptomics and identification of candidate chemosensory genes in antennae of Conogethes punctiferalis (Lepidoptera: Crambidae). J. Asia Pacific Entomol. 19, 911-920. doi: 10.1016/ j.aspen.2016.08.007

Xing, Y., Thanasirungkul, W., Adeel, M. M., Yu, J., Aslam, A., and Chi, D. F. (2021). Identification and analysis of olfactory genes in Dioryctria abietella based on the antennal transcriptome. Comp. Biochem. Physiol. D Genomics Proteomics 38, 100814. doi: 10.1016/j.cbd.2021.100814

$\mathrm{Xu}, \mathrm{W}$. (2020). How do moth and butterfly taste?-Molecular basis of gustatory receptors in Lepidoptera. Insect Sci. 27, 1148-1157. doi: 10.1111/1744-7917. 12718

$\mathrm{Xu}, \mathrm{W}$., and Anderson, A. (2015). Carbon dioxide receptor genes in cotton bollworm Helicoverpa armigera. Naturwissenschaften 102:1260. doi: 10.1007/ s00114-015-1260-0

Xu, W., Papanicolaou, A., Zhang, H. J., and Anderson, A. (2016). Expansion of a bitter taste receptor family in a polyphagous insect herbivore. Sci. Rep. 6:23666. doi: $10.1038 /$ srep23666

Xu, W., Zhang, H. J., and Anderson, A. (2012). A sugar gustatory receptor identified from the foregut of cotton bollworm Helicoverpa armigera. J. Chem. Ecol. 38, 1513-1520. doi: 10.1007/s10886-012-0221-8

Xu, W., Zhang, H., Liao, Y., and Papanicolaou, A. (2021). Characterization of sensory neuron membrane proteins (SNMPs) in cotton bollworm Helicoverpa armigera (Lepidoptera: Noctuidae). Insect Sci. 28, 769-779. doi: 10.1111/17447917.12816

Yang, B., Ozaki, K., Ishikawa, Y., and Matsuo, T. (2015). Identification of candidate odorant receptors in Asian corn borer Ostrinia furnacalis. PLoS One 10:e0121261. doi: 10.1371/journal.pone.0121261

Yang, H., Dong, J., Sun, Y., Hu, Z., Lv, Q., and Li, D. (2020a). Antennal transcriptome analysis and expression profiles of putative chemosensory soluble proteins in Histia rhodope Cramer (Lepidoptera: Zygaenidae). Comp. Biochem. Physiol. D Genomics Proteomics 33, 100654. doi: 10.1016/j.cbd.2020. 100654

Yang, H., Dong, J., Sun, Y. L., Hu, Z., Lyu, Q. H., and Li, D. (2020b). Identification and expression profiles of candidate chemosensory receptors in Histia rhodope (Lepidoptera: Zygaenidae). PeerJ 8, e10035. doi: 10.7717/peerj. 10035

Yang, K., and Wang, C. Z. (2021). Review of pheromone receptors in heliothine species: expression, function, and evolution. Entomol. Exp. Appl. 169, 156-171. doi: 10.1111/eea.12982

Yang, S., Cao, D., Wang, G., and Liu, Y. (2017). Identification of genes involved in chemoreception in Plutella xyllostella by antennal transcriptome analysis. Sci. Rep. 7:11941. doi: 10.1038/s41598-017-11646-7
Yang, Y., Li, W., Tao, J., and Zong, S. (2019). Antennal transcriptome analyses and olfactory protein identification in an important wood-boring moth pest, Streltzoviella insularis (Lepidoptera: Cossidae). Sci. Rep. 9:17951. doi: 10.1038/ s41598-019-54455-w

Yao, C. A., Ignell, R., and Carlson, J. R. (2005). Chemosensory coding by neurons in the coeloconic sensilla of the Drosophila antenna. J. Neurosci. 25, 8359-8367. doi: 10.1523/JNEUROSCI.2432-05.2005

Yin, N. N., Nuo, S. M., Xiao, H. Y., Zhao, Y. J., Zhu, J. Y., and Liu, N. Y. (2021). The ionotropic receptor gene family in Lepidoptera and Trichoptera: annotation, evolutionary and functional perspectives. Genomics 113, 601-612. doi: 10.1016/j.ygeno.2020.09.056

Yuvaraj, J. K., Andersson, M. N., Zhang, D. D., and Löfstedt, C. (2018). Antennal transcriptome analysis of the chemosensory gene families from Trichoptera and basal Lepidoptera. Front. Physiol. 9:1365. doi: 10.3389/fphys.2018.0 1365

Zeng, F. F., Sun, X., Dong, H. B., and Wang, M. Q. (2013). Analysis of a cDNA library from the antenna of Cnaphalocrocis medinalis and the expression pattern of olfactory genes. Biochem. Biophys. Res. Commun. 433, 463-469. doi: 10.1016/ j.bbrc.2013.03.038

Zeng, F. F., Zhao, Z. F., Yan, M. J., Zhou, W., Zhang, Z., Zhang, A., et al. (2015). Identification and comparative expression profiles of chemoreception genes revealed from major chemoreception organs of the rice leaf folder, Cnaphalocrocis medinalis (Lepidoptera: Pyralidae). PLoS One 10:e0144267. doi: 10.1371/journal.pone.0144267

Zhang, D. D., and Löfstedt, C. (2015). Moth pheromone receptors: gene sequences, function, and evolution. Front. Ecol. Evol. 3:105. doi: 10.3389/fevo.2015.0 0105

Zhang, H. J., Anderson, A. R., Trowell, S. C., Luo, A. R., Xiang, Z. H., and Xia, Q. Y. (2011). Topological and functional characterization of an insect gustatory receptor. PLoS One 6:e24111. doi: 10.1371/journal.pone.002 4111

Zhang, H. J., Xu, W., Chen, Q. M., Sun, L. N., Anderson, A., Xia, Q. Y., et al. (2020). A phylogenomics approach to characterizing sensory neuron membrane proteins (SNMPs) in Lepidoptera. Insect Biochem. Mol. Biol. 118:103313. doi: 10.1016/j.ibmb.2020.103313

Zhang, J., Wang, B., Dong, S., Cao, D., Dong, J., Walker, W. B., et al. (2015). Antennal transcriptome analysis and comparison of chemosensory gene families in two closely related noctuidae moths, Helicoverpa armigera and H. assulta. PLoS One 10:e0117054. doi: 10.1371/journal.pone.011 7054

Zhang, L. W., Kang, K., Jiang, S. C., Zhang, Y. N., Wang, T. T., Zhang, J., et al. (2016). Analysis of the antennal transcriptome and Insights into olfactory genes in Hyphantria cunea (Drury). PLoS One 11:e164729. doi: 10.1371/journal. pone. 0164729

Zhang, S., Zhang, Z., Wang, H., and Kong, X. (2014). Antennal transcriptome analysis and comparison of olfactory genes in two sympatric defoliators, Dendrolimus houi and Dendrolimus kikuchii (Lepidoptera: Lasiocampidae). Insect Biochem. Mol. Biol. 52, 69-81. doi: 10.1016/j.ibmb.2014. 06.006

Zhang, T., Coates, B. S., Ge, X., Bai, S., He, K., and Wang, Z. (2015). Male- and female-biased gene expression of olfactory-related genes in the antennae of Asian corn borer, Ostrinia furnacalis (Guenée) (Lepidoptera: Crambidae). PLoS One 10:e0128550. doi: 10.1371/journal.pone.0128550

Zhang, Y. N., Jin, J. Y., Jin, R., Xia, Y. H., Zhou, J. J., Deng, J. Y., et al. (2013). Differential expression patterns in chemosensory and non-chemosensory tissues of putative chemosensory genes identified by transcriptome analysis of insect pest the purple stem borer Sesamia inferens (Walker). PLoS One 8:e69715. doi: 10.1371/journal.pone.0069715

Zhang, Y. N., Ma, J. F., Sun, L., Dong, Z. P., Li, Z. Q., Zhu, X. Y., et al. (2016). Molecular identification and sex distribution of two chemosensory receptor families in Athetis lepigone by antennal transcriptome analysis. J. Asia Pacific Entomol. 19, 571-580. doi: 10.1016/j.aspen.2016.05.009

Zhang, Y. N., Qian, J. L., Xu, J. W., Zhu, X. Y., Li, M. Y., Xu, X. X., et al. (2018). Identification of chemosensory genes based on the transcriptomic analysis of six different chemosensory organs in Spodoptera exigua. Front. Physiol. 9:432. doi: $10.3389 /$ fphys.2018.00432

Zhang, Y. N., Zhu, X. Y., Ma, J. F., Dong, Z. P., Xu, J. W., Kang, K., et al. (2017). Molecular identification and expression patterns of odorant binding protein 
and chemosensory protein genes in Athetis lepigone (Lepidoptera: Noctuidae). PeerJ 5, e3157. doi: 10.7717/peerj.3157

Zhang, Z. J., Zhang, S. S., Niu, B. L., Ji, D. F., Liu, X. J., Li, M. W., et al. (2019). A determining factor for insect feeding preference in the silkworm, Bombyx mori. PLoS Biol. 17:e3000162. doi: 10.1371/journal.pbio.3000162

Zhao, H. X., Xiao, W. Y., Ji, C. H., Ren, Q., Xia, X. S., Zhang, X. F., et al. (2019). Candidate chemosensory genes identified from the greater wax moth, Galleria mellonella, through a transcriptomic analysis. Sci. Rep. 9:10032. doi: 10.1038/ s41598-019-46532-x

Zhu, J. Y., Xu, Z. W., Zhang, X. M., and Liu, N. Y. (2018). Genome-based identification and analysis of ionotropic receptors in Spodoptera litura. Naturwissenschaften 105, 38. doi: 10.1007/s00114-018-1563-z

Zhu, X. Y., Xu, J. W., Li, L. L., Wang, D. Y., Zhang, M. L., Yu, N. N., et al. (2020). Analysis of chemosensory genes in Semiothisa cinerearia reveals sexspecific contributions for type-II sex pheromone chemosensation. Genomics 112, 3846-3855. doi: 10.1016/j.ygeno.2020.06.042
Conflict of Interest: The authors declare that the research was conducted in the absence of any commercial or financial relationships that could be construed as a potential conflict of interest.

Publisher's Note: All claims expressed in this article are solely those of the authors and do not necessarily represent those of their affiliated organizations, or those of the publisher, the editors and the reviewers. Any product that may be evaluated in this article, or claim that may be made by its manufacturer, is not guaranteed or endorsed by the publisher.

Copyright $\odot 2021$ Wang, Wu, Li, Nuo, Yin and Liu. This is an open-access article distributed under the terms of the Creative Commons Attribution License (CC BY). The use, distribution or reproduction in other forums is permitted, provided the original author(s) and the copyright owner(s) are credited and that the original publication in this journal is cited, in accordance with accepted academic practice. No use, distribution or reproduction is permitted which does not comply with these terms. 